\title{
ATELIER
}

\section{J.-B. CARPEAUX}

(Deuxième et dernière Vente) 



ATELIER

\section{J.-B. CARPEAUX}

(Deuxième et dernière Vente) 


\section{CONDITIONS DE LA VENTE}

Elle sera faite au comptant.

Les acquéreurs paieront 10 o en sus des enchères.

\section{AVIS}

Les ouvres de Carpeaux, comprises au présent Catalogue, sont vendues sans aucun droit de reproduction, en quelque matière et en quelque grandeur que ce soit (à l'exception des cuivres pour eaux-fortes).

\section{NOTA}

Toutes les sculptures non signées, à part les modèles en bronze, sont revêtues d'un cachet ovale, soit en cuivre, soit en cire, et portant l'annotation: Propriélé Carpeaux. Ces deux mots séparés par un aigle, les ailes éployées.

Les dessins et albums de Carpeaux, figurant au présent Catalogue et qui ne sont pas signés par l'artiste, portent l'estampille aux initiales J. B. C., entrelacées.

Les héritiers de Carpeaux se réservent, vis-à-vis des acquéreurs, le droit de reproduction des nos $125,156,160,161,234,239,240$, 242 (9 pièces), 253 (5 pièces), droit strictement limité à la publication prochaine d'une édition de luxe, à tirage restreint, d'une Histoire du Siège et de la Commune de Paris, par M. Victor Margueritte. 


\section{ORDRE DES VACATIONS}

\section{LUNDI 8 DÉCEMBRE}

Sculptures................ . . I a I I 6

MARDI 9 DÉCEMBRE

Tableaux et dessins par Carpeaux . . . . . . . 117 à 255

Cuivres gravés pour eaux-fortes . . . . . . . . . . 256 à 259

Dessins par Eug. Delacroix. . . . . . . . . $\quad 260$ à 292 



\section{CATALOGUE}

$\mathrm{DE}$

\section{SCULPTURES ORIGINALES}

TERRES CUITES, PLATRES, BRONZES

Groupes, Statuettes, Bustes, Médaillons, Esquisses

\section{TABLEAUX ET DESSINS \\ Par J.-B. CARPEAUX}

Dessins par Eug. DELAOROIX

DONT LA VENTE AURA LIEU A PARIS

\section{GALERIE MANZI，JOYANT}

I5, rue de la Ville-l'Évêque

LES LUNDI 8 ET MARDI 9 DÉCEMBRE 1913, A 2 HEURES

$$
\text { COMMISSAIRE-PRISEUR }
$$

$M^{\mathrm{e}}$ Henri BaUdoIN, Successeur de M. Paul CHEVALLIER

I0, rue de la Grange-Batelière

\section{EXPERTS}

MM. DURAND-RUEL \& FILS 16, rue Laffitte

PARIS
MM. J. \& G., BERNHEIM JEUNE

25, boulevard de la Madeleine

et 36 , avenue de l'Opéra

$$
\text { E:XPOSITION:S }
$$

Particulit̀re : Le Samedi 6 décembre I $g$ I3, de I h. $1 / 2$ à 6 heures

Publique: Le Dimanche 7 décembre 1913 , de $I$ h. $1 / 2$ d̀ 6 heures 



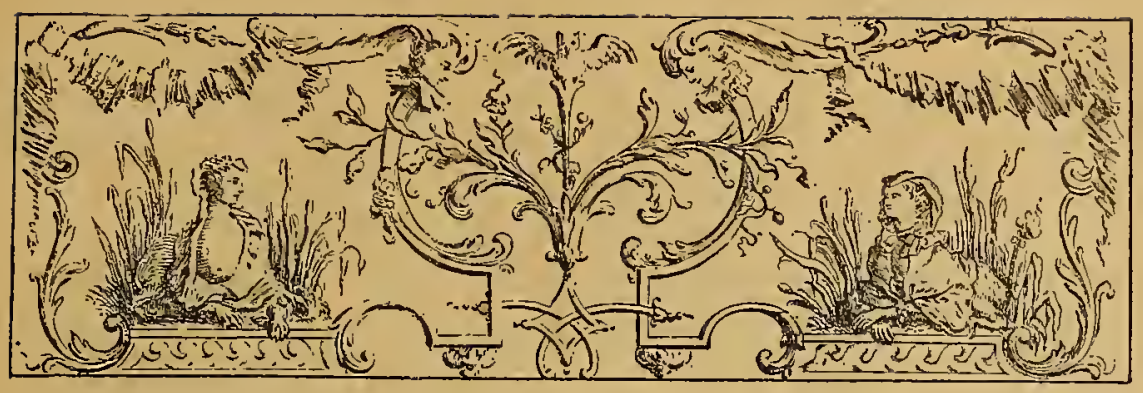

\section{P R É F A C E}

Je signalais, le 30 mai dernier; cet événement sensationnel : la dispersion des principaux chefs-d'œuvre de Carpeaux. L'exposition, qui précéda la vente, fut un triomphe. Dans cette galerie Manzi, cadre à souhait pour le merveilleux ensemble, il semblait qu'on assistât à une révélation : le génie de Carpeaux surgissait, vivant. Beaucoup criaient au miracle, comme s'ils découvraient, brusquement, les dons radieux du statuaire illustre.

Trente-neuf ans après le rayonnement de cette vie, et au lendemain des commémorations d'où, à l'École Nationale des Beaux-Arts, à la Centennale, au Salon d'Automne, à Londres, à Bruxelles, au Jeu de Paume, le noble nom ressuscitait, chaque fois plus éclatant et plus jeune, - pourquoi, succédant à ces baptêmes du temps, cette sorte. de surprise devant l'éclat de la consécration définitive?

Hélas! nous vivons si vite, tant d'éphémères réputations nous sont imposées, d'un jour à l'autre, un si trépidant chaos nous emporte que, pour le commun des mortels, Carpeaux reste uniquement "l'homme de la Danse. „Bien peu ont pénétré toute l'œuvre. Et puis un insuffisant recul nous sépare des jours qui revivent là sans qu'aient disparu, de la scène actuelle, tous les acteurs que le Maître modela. Pour que le soleil des morts, la Gloire, enveloppe de sa pleine lumière les figures qu'il a choisies, il faut qu'il se dégage des brumes du crépuscule, monte haut, sur l'horizon. A présent, c'est chose faite, pour Carpeaux. Après l'epreuve de l'ombre, celle du feu; il a rejoint Rude et Barye, dans cet éblouissant empire où l'art du $\mathrm{x}_{1} \mathrm{x}^{\mathrm{c}}$ sičcle réserve une place encore à Rodin.

Cela n'empêchera peut-être point ceux qui admirèrent, si passionnément, et qui se sont disputé chez Manzi une partie des reliques pieu- 
sement gardées jusque-là, dans l'atelier du boulevard Exelmans, de s'étonner à l'annonce d'une nouvelle exposition, si proche de la première. Nous ne connaissons plus, de nos jours, ce qu'est capable de réaliser le formidable labeur du génie, quand il n'a pu, ni voulu, s'accorder aucune trêve, et quand il eut surtout, pour s'exprimer, plusieurs modes.

A còté de Carpeaux sculpteur, il y a, non moins extraordinaires, Carpeaux peintre et Carpeaux dessinateur. Un maitre complet et une cuvre immense. Le plus frappant exemple de ce que peut la volonté au service d'une foi. Paurre et de "petite extrace ", comme disait Villon, c'est de son seul et tenace effort que le petit Valenciennois, s'arrachant à J'orniere, fraye la route devant lui. Rien de tel, pour passer maitre, que la rude école de la nécessité. On y reste, ou bien l'on en sort trempé. Cette vie courte fut remplie d'autant d'ouvres que de jours. C'est pourquoi, après avoir enrichi nos musées et nos palais, elle suffit à alimenter, coup sur coup, deux grandes ventes, sans épuiser l'admiration.

Et sans doute elles sont à jamais dispersées, ces pièces capitales qui firent l'autrait de la vacation de mai, et qui eussent dû faire l'orgueil de nos musées, si, plus français qu'eux, un musée danois ne s'en était assuré la jouissance. Oú s'en ira, disais-je avec l'espoir que l'État les saurait garder, la divine Danse, éternisant dans sa rose terre toute la gràce fëminine, avec l'allégresse de vivre? Où s'en ira l'Ugolin, digne de Michel-Ange? Il faudra dorénavant faire le voyage de la Glyptolhèque, à Copenhague, pour revoir ces chefs-d'œuvre, au milieu de ceux qu'avait assemblés dejà le culte avisé de M. Jacobsen (1). Constatation mélancolique. Est-ce que, si bien représenté que puisse ètre dans nos galeries un sculpteur comme celui-ci - et en dépit de la salle Carpeaux au Louvre, et du Musée Carpeaux à Valenciennes - une nation ne devrait pas toujours tenir à honneur de conserver à sa race l'essence mème de son génie? Est-elle jamais assez riche de tels trésors ?

Il subsiste en effet, tant était opulent le sanctuaire du boulevard Exelmans, de quoi illustrer, avec tolite la série des maquettes, avec nombre de statuettes charmantes, la collection de sculpture la plus belle, comıne, avec la série saisissante des peintures et des dessins, de

(1) "Il reste menne a savoir si ces deux dernicres acquisitions ne sont pas tellement imporiantes dans la production de Carpeaux, que cet artiste se laisse maintemant mieux étudier dans la Glyptothique de Copenhague qu'en France. " Vationaltidende, $=5$ juillet $: 913$. 
quoi composer un musée inattendu, d'où un Carpeaux nouveau, maître de la couleur et des lignes, sort criant de vie, aussi ardent, aussi profond, aussi émouvant que l'animateur de la Flore et le magicien de la Danse.

La sculpture d'abord.

Ces maquettes où dans la terre séchée palpite nue la première vision! Ce limon encore frémissant qui garde, avec l'empreinte des doigts, l'àme créatrice !... Boulettes fébrilement pétries, "ébauches de statues jamais faites, idées entr'aperçues, " (I) - tout le passionnant secret de la gestation, tout un monde de menus chefs-d'œuvre : les formes en travail, le mouvement cueilli, la pensée dans sa fleur...

Puis ce sont, plâtres ou cires, les originaux en grandeur naturelle ou en réduction de bon nombre d'œuvres célèbres, leurs variantes heureuses, leurs esquisses: Paul et Virginie, le Projet de Décoration pour l'Hòtel de Ville de Valenciennes, les Quatre Parties du Monde, l'Enfant au Cor, les charmants Napolitains, le Rieur et la Rieuse (plàtres et bronzes)... Voici, en réduction encore, des plâtres originaux de Dapltnis et Chloé, du Chinois; des bronzes de l'Amour désarmé et de la Jeunte fille à la Coquille... Voici une pièce tragique qui relève de l'histoire avant l'art, le Masque de Napoléon III, moulage en plâtre fait par Carpeaux après la mort de l'Empereur. Voilà enfin les étonnants portraits, en réductions originales : l'Alexandre Dumas fils, - celui-ci portant en dédicace : "all" Huomo penserioso ", en face duquel Dumas lui-même disait : "Ce diable d'homme fait plus virant que la vie " (2) - la Duciesse de M..., Mademoiselle F... - et l'Espérance et l'Amour à la Folie, et les médaillons... morceaux admirables, dont on avait, en mai, remarqué l'absence.

Voilà de quoi, n'est-il pas vrai, satisfaire ceux qui ont souci de la gloire du maître, les plus difficiles fervents.

La peinture, maintenant.

Carpeaux, on le sait, c'est le Second Empire tout entier, incarné dans la terre et le plàtre, dans le bronze et le marbre. Ces dures, ingrates matières, elles bougent, frissonnent avec l'heure fixée, en son immobile survie. Les critiques les plus autorisés ont noté cette identification.

"La carrière de Carpeaux, - écrit Gabriel Hanotaux, qui ne craint

(1) Maurice Guillemot. - Préface du catalogue de l'Exposition des œuvres de Carpeaux à l'Ecole Nationaie des Beaux-Arts. Mai i \&9y.

(2) J. Claretie Le Temps, 16 mai 1913. 
"pas de le comparer à l'observateur. Taine, - se limite aux dix-huit " années du Second Empire, qui vit surgir une démocratie et s'écrouler " une légende. Tout ce que cette époque eut de séduisant et de décevant " palpite dans son œuvre... Carpeaux est aussi d'une intelligence singu" lière, d'une acuité presque déconcertante... Rien ne lui échappe, son " imagination douloureuse pénètre tout, dévoile tout, déshabille tout. "Le trait caractéristique le frappe tout de suite. Et comme il travaille avec passion, avec enthousiasme, la saillie physique et morale surgit violemment. Il sent et il crée intense (1)."

De même, le savant M. André Michel a noté : "S'il est vrai, comme "veut Stendhal, que le but essentiel des ouvres d'art soit de nous "représenter la manière habituelle dont les hommes et les femmes, pour " qui ces cuvres furent faites, cherchèrent ou rèvèrent la beauté, c'est " dans l'œuvre de Carpeaux qu'on trouvera, comme dans un témoin " fidèle, une part de vraies "Confessions " du Second Empire (2)."

Gustave Geffroy observe enfin, de son còté : "La particularité du " génie de Carpeaux est aujourd'hui précisée. C'est l'expression, la péné" tration d'un milieu. C'est son aliment, sa force trouvée dans l'instant; " c'est sa date... Lil sensation qu'on emporte, c'est que l'on vient de " vivre le Second Empire, c'est que Carpeaux est très fortement, très "profondément, un homme de ce temps-là, un artiste sans cesse ému " par la vie directement observée ct ressentie, et qui devient tout à " coup, par la reculée du temps, un historien (3)."

Un historien, et le plus évocateur qui soit! Un historien à la Michelet, mais puisant à la source vive, non au fleuve séché des bibliothèques. Or, ce qui est vrai de Carpeaux sculpteur, ne l'est pas moins de Carpeaux" peintre. Et, peintre, il le fut toute sa vie. Il l'est splendidement, des la Villa Médicis, depuis cette Vue du Tibre et cette Messe de minuit à Rome (4), digne, celle-ci, du plus impressif Manet, et, celle-là, du plus large Corot, jusqu'à l'admirable portrait de sal fin, - effigie émouvante où dans les traits ravagés, les joues creuses aux dures pommettes, le front puissant, les mèches grises, et dans le regard brûlant sous les paupières clignées, se débattent aux prises l'amertume de la mort proche, ct le sursaut de la vie, dardant sa suprême flamme.

(r) Gabriel Hanotaux. - Carpeaux. Figaro, 4 juin 1912.

(2) André Michel. - Jean-Baptiste Carpeaux. Revue Hebdomadare, 9 mars 1912.

(3) Gustave Geffroy. Priface de la galerie Carpeaux, par Ch. Carpeaux.

(4) La Messede minuit à Rome est de $185 y$, et Manet débute, inconnu, au Salon de 1861 . 
Les parents de Carpeaux qui eussent aimé le voir géomètre, ou décorateur, rêvaient surtout de faire de lui un architecte. C'est donc à la pierre que dès l'enfance il est voué. Heureusement il cachait toujours dans ses poches un crayon, - et de griffonner ! En $1848,-$ il a vingt et un ans et n'a pas encore manié le pinceau, - il parie avec son ami BrunoChérier de peindre, dans le tableau que prépare celui-ci, la figure centrale. Et c'est le Vieux Sergent, conservé au Musée de Valenciennes. Gauche début de tant de toiles où la vie, - il faut toujours en revenir là avec Carpeaux, c'est l'expression-type, - se meut avec tant d'aisance qu'elle n'est jamais arrêtée, continue de vivre.

La peinture, il l'adore comme un amoureux jaloux de ne pouvoir jamais assez posséder sa maîtresse. A Rome, il peint à chaque répit de l'ébauchoir. Il fait, en 1863 , un voyage spécial en Belgique pour étudier Rubens, ne quitte pas le pinceau durant ces semaines enivrées. « J'ai barbouillé des toiles, écrit-il à un ami. On dit que je fais de grands progrès en peinture. Est-ce vrai? Cette étude me procure des charmes qui remplissent mon âme d'une secrète espérance. J'aime cet art avec passion. Il me révèle plus que ma chère sculpture. "Sa chère sculpture! Parfois, aux soirs de lutte, nous la lui entendons maudire, il déplore de n'avoir pu se donner tout à la rivale qui le captive.

"Il aime la pâte généreuse qu'il manie avec une virtuosité instinctive, et qu'il jette sur la toile comme les boulettes de terre d'une maquette, en taches, en éclaboussures, en larges coulées. Même dans les esquisses les plus sommaires, la structure est d'un sculpteur, mais la sensation initiale est bien d'un peintre qui part d'une vision colorée des choses et que préoccupe le problème de l'éclairage... Si c'est à la 'matière et aux moyens de la sculpture qu'il a confié ses créations les plus fortes, il a toujours eu un ceil de peintre, sensible au spectacle fugitif et toujours renouvelé de la vie. Il eut le don, et il voulut l'avoir (I). "C'est ainsi que s'exprine, avec autorité, M. Paul Jamot. le distingué conservateur adjoint du Musée du Louvre, dans une remarquable étude sur Carpeaux peintre.

Ses maitres? Incontestablement d'abord Michel.Ange, son Dieu, aussi bien dans l'œuvre picturale que dans l'œuvre sculpturale. Puis Delacroix, dont l'influence est flagrante (2). Enfin, et sans cesse, celle des

(1) Paul Jamot. Gaiette des Beaux-Arts : Carpeaux peintre et graveur. Sept. 1908.

(2) Aussi bien trouvera-t-on au catalogue, parmi les dessins de Carpeaux, toul un lot remarquable d'originaux de Delacroix. Carpeaux l'aimait, non moins pour sa couleur que pour sa science, et s'était plu à recueillir pieusement tout ce qu'il avai? 
grands maîtres flamands, pas à pas suivis, approchés dans ses études. Carpeaux d'ailleurs n'est-il pas né sur la marche de ce pays de Flandre, imprégné du sang espagnol? Il n'a, pas plus que Manet, vu jamais le Musée de Madrid, et comme lui pourtant il a, avec les maîtres de Madrid, une affinité. Legs lointain de l'atavisme? Hautes parentés de l'esprit?...

" Il cherche d'instinct la tonalité chaude, la couleur cuite, les taches éclatantes sur des dessous sombres et roux. Il pouvait avoir sur Manet la supériorité d'une construction sûre, et il joignait à cette solide vertu des facultés brillantes et diverses, le sens voluptueux de la beauté féminine et même des élégances mondaines, le don d'évoquer le tumulte des foules " (1).

Certes, si l'on songe à l'œuvre sculptée, il serait puéril de regretter que Carpeaux n'ait pu se livrer davantage au démon de la couleur. Peutêtre même le jailli, l'inachevé contribuent-ils à donner, à ses portraits comme à ses esquisses si diverses, cette espèce d'irrésistible attrait que le rêve ajoute, au point de départ de la réalité. E.t pourtant, devant les prestigieuses toiles du Louvre (les deux "Bals aux Tuileries") et devant le célébre "Bal dans la Salle des Maréchaux" — un des bijoux de cette vente - on ne peut s'empècher de se dire : "Quel peintre! Et quel dommage que semblable à son grand ancêtre, le Valenciennois Watteau, dont il se plut à ressusciter la fière et fine silhouette, il n'ait pas eu le temps d'envelopper, d'une lumière féerique toute la vision de cette époque - ombres dorées de nouvelles Fêtes galantes que guette, au tournant de l'heure, le destin tragique!"

On se souvient de ces joyaux du Louvre(2). Ils étincellent. Dans l'un, une magicienne passe; c'est la comtesse de Castiglione au bras de l'Empereur distrait. Un manteau vénitien flotte sur l'uniforme de Napoléon III. Acteurs falots d'un grand drame. Le couple avance, spectral, dans une cour de gloire, sous la splendeur des hauts plafonds... Dans l'autre, l'Impératrice Eugénie, onduleuse, altière, ouvre le bal. Svelte et droit, son cavalier (c'est l'Empereur Alexandre) domine avec

pu du labeur du grand artiste. Que de fois s'est-il émerveillé devant ces feuilles inagistrales ò̀, à l'encre, au crayon, à la sanguine, avec une précision saisissante, un membre écartelé pa!pite encore, où un mouvement est étudié, de l'épiderme à la moelle des os !... Documents doublement précieux, ces pages qu'illustrèrent la main de Delacroix et le visage penché de Carpeaux?

(1) Paul Jamot. Gazette des Beaux-Arts. Ibid.

(2) Entre parentheses, ils sont accrochés, trop haut, loin du regard, au-dessus de deux Diaz (dont les salles Thomy-Thiéry regorgent) et, d'ailleurs, d'intérêt moyen. 
elle le gala, le salut ployant des habits de cérémonie, les épaules nues dans les dentelles... Ce sont des vivants et ce sont des fantòmes. Ils vont dans un éblouissement. On ne sait s'ils vont se préciser, ou s'évanouir. Au chatoiement de cette étrange clarté, une ténèbre secrète s'infuse.

Vision, ai-je dit... C'est le mot. Un visionnaire, seul, a pu rendre l'enchantement de cette poésie, qui serre le cœur. La mème atmosphère poudroie autour du "Bal dans la Salle des Maréchaux". Les souverains, sur une estrade, contemplent la foule tournoyante et parée, cette sarabande qui, en riant, roule au gouffre. Il n'y a là que de la joie et des rires, et je ne sais quel vertige aussi qui avertit que dans cet air léger, l'invisible planke. Inconscience et fatalité. Le regard qu'on jette sur celte espèce de Danse des Morts,' si lumineuse, une mélancolie poignante le prolonge.

La place de ce chef-d'œuvre, dont la réapparition à l'Exposition du Jeu de Paume suscita tant d'enthousiasme et de compétitions, n'est-elle pas marquée? Et ne serait-ce pas, vraiment, une perte publique si nous lui royions prendre tout autre chemin que celui de sa maison: le Louvre? Celui-ci pourrait encore s'enorgueillir, à juste titre, de plusieurs autres toiles, non moins précieuses, dans cet étonnant ensemble pour la dernière fois réuni, et dont la plupart des savoureux morceaux sont connus depuis la belle Exposition rétrospective organisée au Salon d'Automne de 1907 par les soins de M. Edouard Sarradin ( $\mathrm{r}$ ).

C'est la fameuse grisaille de la nanse, où l'un des corps de Bacchante s'enlève en chair - étude admirable qui, une fois déjà, avait quitté la galerie d'Auteuil et que Mme Carpeaux, revoyant à la Rétrospective, voulut à tout prix replacer parmi les chefs-d'œuvre conservés sous le toit familial. Voilà des visions de nuages, d'exquis portraits tels que cette tète d'Italienne, celui de $M^{\text {lle }}$ Barbe de $M$., de puissantes études d'après Michel-Ange, le Corrège, Rubens, des paysages, des esquisses... Voilà ces "Roses dans un verre", toile surnaturelle qui fait songer, avec plus d'éclat, au doux modelé de Carrière. Des scènes religieuses, des Pieta dramatiques, d'une douleur si passionnée. Un étonnant Départ de troupes dans le brouillard...

(1) En dehors du Louvre, des morceaux de peinture admirables at des dessins out dejà été dispersés chez des collectionneurs tels que MM. Leprieur, Jacques Doucet, Henry lapauze, Paul Iamot, Guiltrey, le baron Reinach, Beurdeley, baron Vitia, baron Alphonse de Rothschild, Raymond Kochlin, etc.. etc.

Des sculptures sont entrées dans les galeries du baron Robert de Rothschild, de la comtesse Roderer. Mme Chadbourne, Mime Mahieu d'Andress, MM. Chouallard, Paul Lillaz. Lafion, Gulbenkian, etc., ctc.

M. Gulbenkian a depose au louve ses acquisitions les plus importantes: La Flore accroupie. marbre, limonr blessé, models en bronze, et le busie de Bruno Chérier, plâtre original. 
Voilà enfin, pour résumer ces notes trop brèves sur Carpeaux peintre, les plus prodigieux " essais » qui se puissent voir, les inappréciables témoins de ce qu'a été, et ce qu'aurait pu être dans cet art un frère des Manet, des Ribot, des Ricard, et qui, sans doute, les eùt tous dépassés, si son autre vocation, l'élevant aux sommets, lui eut laissé le loisir de prendre toute sa place.

Place à part, singulière, et très haute.

Restent les dessins.

J'ai dit, dans une précédente page ( 1 ), le miracle de ces milliers de croquis pris au jour le jour, et à la diable, toute une existence durant. Point d'heure sans un trait. C'est ainsi que Carpeaux amassa, infatigablement, ces fulgurantes observations, au hasard d'innombrables feuilles volantes, ct dans la série de ces calepins de poche qui jamais ne le quittaient. On en compte des centaines. Rien qu'à Valenciennes 107 réduits à 104 par les feuillets détachés et exposés; quantité au Louvre et à la Bibliothéque des Beaux-Arts. D'autres encore (et ce ne sont pas les moins précieux) dans les mains de ses enfants.

C'étaient, ces humbles carnets, sa glorieuse carte d'identité. Ils portaient souvent, de cette nerveuse écriture dont il barrait le papier bleu, blanc, ou quadrillé : "A rapporter, en cas d'accident, à J.-B. Carpeaux, " et l'adresse. Dessins mêlés de réflexions, de mementos et où se lit jusquau brouillon d'un discours préparé pendant le siège Ce qui frappe, au point de surprendre, dans cet amas de pages qui forment le plus groullant "livre de vie ", c'est, avec une science suprême, le bouillonnement continu de la pensée. Ce cerveau perpétuellement enfante. En recréant, il crée; c'est le don génial. Un monde de formes, de lignes, de couleurs est en fusion dans ces menus traits, ces raccourcis si sùrs, si nets, trouvés et non cherchés. Dessins poussés ou schématiques, - ceux-ci ne suggérant pas moins, - un cinématographe d'art trépidant, hallucinant! Illustration d'une vie et d'une époque.

"Il est impossible, - je cite encore M. Paul Jamot, - qu'un "sculpteur ne soit pas un dessinateur. Et s'il a du génie, les croquis " où s'annonce la première pensée d'une statue ou d'un groupe auront le “ même intérêt et la même beauté que tel crayon où un grand peintre " a cherché l'ordonnance de son œurre... La collection des dessins de "Carpeaux est un des plus beaux parmi ces répertoires où nous cher-

(1) Atelier J.-B. Carpeaux, préface du Catalogue de la première vente, mai ig13. 
" chons la pensée frémissante d'un maître méditant son cuvre, ou se "livrant avec enthousiasme aux multiples suggestions de la vie..."

Et plus loin : "Tous les procédés lui sont bons: plume, lavis, " mine de plomb, fusain, crayon noir, sanguine, pastel, gouache, " aquarelle... mais à tout il préfère le papier gris ou bleu, souvent assez " foncé, sur lequel le crayon Conté court en frottis légers, balafre les " ombres de hachures violentes, souligne d'un trait écrasé la structure "d'un visage ou le contour d'un corps, tandis que des rehauts de "blanc font saillir les reliefs et miroiter les lumières (1). "

L'improvisation, à ce degré de maitrise, n'est pas seulement, comme on le pourrait croire, le résultat d'heureux dons. C'est le fruit d'un âpre, d'un incessant labeur. Souvenons-nous des nobles lignes écrites par Carpeaux à la veille de sa mort et qui jettent, sur sa studieuse jeunesse, un jour révélateur : "Je parcourais les rues de la Ville Eter" nelle le crayon à la main, interprétant des scènes variées sous les yeux " de mesamis qui ne comprenaient pas comment je pouvais voir dans " la nature des sujets si élevés, si tendres, si caractéristiques. Je leur " montrais tous les jours l'art de voir, et bien peu pouvaient me suivre.

"Pourquoi? c'est qu'ils n'avaient que l'étude plastique de la nature. Ils " avaient négligé l'enthousiasme qui électrise l'artiste et lui fait trouver " des accents sublimes pour s'élever au-dessus du niveau de la vie ordi" naire, c'est ce que j'appelle la seconde vue."

Curieux mot, et divinateur, sous la plume de ce "voyant" qui s'ignorait, modestement effacé devant le travailleur sans merci. Car il ne faut pas se lasser de le répéter : dans le grand homme touché par la splendeur et la faveur impériales, il y avait avant tout, avec l'artisan acharné à la perfection, un artiste d'indépendance hautaine, asservi à ce but unique comme à une religion : l'Art. Un indépendant, que dis-je, un intransigeant! Les Zoïle du temps le lui firent bien voir. "Le dessin libre, écrivait-il encore, tout est là. Mettez le trait dans l'impression fugitive, conservez l'élan; ne vous faites pas l'esclave du procédé, ne ciselez pas, - arez une âme! "Une âme, et une âme volontaire, voilà tout l'enseignement de Carpeaux, donné par lui-même. C'est le secret de cette création prodigieuse.

M. Edouard Sarradin, un des critiques d'art qui ont le plus finement analysé, aimé Carpeaux, a dégagé avec force ces grandes lignes, règles d'une vie. "Il avait acquis dans une existence singulièrement indépen" dante un pouvoir d'indiscipline en quelque sorte providentiel. C'est

(I) Paul Jamot, Gajette des Beaux-Arts. Ibid. 
"qu'il était doué d'un puissant instinct que servait sans cesse une volonté " superbe, éperonnée, fortifiée par l'adversité (1)."

Dès lors, comme on vous comprend mieux et comme on vous chérit davantage, dessins, études plus humbles, premiers "états " d'une grande àme !... On en trouvera ici beaucoup. Embryons où la Beauté est en germe; enfants souples et drus qui ont la grâce, déjà, d'êtres complets; et aussi, en quantité, ces pages magistrales qui vont aussi loin, dans le bonheur total de l'expression, que le génie peut pousser.

Et c'est, à côté du thème vénéré, de la superbe série inspirée du "Jugement Dernier ", de Michel-Ange, la foule des projets de statues, souvent irréalisées, croquis d'après Watteau, croquis d'enfants, croquis de chevaux, études préliminaires pour ses œuvres, scènes populaires dans la rue, au théâtre... C'est la famille impériale surprise dans son intimité, le charmant "Petit Prince " pendant sa leçon de danse, sa leçon de violon... C'est Napoléon rèvant, soucieux dẻjà, puis l'Empereur en représentation, le souverain affable des soirs de gala, son élégance lourde, lasse... C'est l'Impératrice en toilette de bal... Ce sont, enfin, les jours douloureux de Chislehurst, le shaliespearien crayon d'après nature du vaincu de Sedan, dans son cercueil, en grand uniforme, traits déjà bouffis, poitrine barrée du grand cordon, et, aux pieds, la couronne à l'N funéraire. Entre ces jetıx bornes de la destinée tient l'émouvante évocation de la guerre: soldats en marche, réquisition de chevaux, ambulances, pièces en batterie, proclamation de la République, morts còte à cóte attendant la fosse, incendies... Toutes les heures terribles sont là. Carpeaux les a vécues, les nerfs à vif, enfermé dans Paris, hôte du palais du Luxembourg, durant les longs mois du siège.

Son existence entière, nous la touchons, tant dans les nombreux dessins encadrés que dans ces albums bourrés de merveilles - (tel certain cahier rouge où il a groupé, collé lui-mème plus de deux cents compositions et études), - dans ces albums reconstitués avec un soin pieux, ces carnets de poche devenus introuvables... A travers tout cela, que de chefs. d'œuvre restés aux limbes! Et comme elle tait encore plus regretter, cette mine d'études, la mort prématurée! Où se serait-il arrêté, cet infatigable pionnier du Vrai et du Beau?

Concluons.

L'un des plus grands sculpteurs qui illustrent l'art français, J.-B. Car-

(1) Edouard Sarradin. - Préface du Catalogue de l'Exposilion Rétrospective au Salon d'Automne, 1907 . 
peaux, nous émeut plus peut-ètre que ses émules, par la fièvre ardente de sa vie. Et, sans doute, il demeure par-dessus tout l'immortel auteur de la Danse, de la Flore et de la Fontaine du Luxembourg, en mème temps que, dans ses bustes, l'historien-poète d'une époque. Comme les maitres suprêmes, cet amant passionné de la vie mérita la fortune de relier, par un maillon incorruptible, l'heure qu'il vécut en l'exprimant, à la chaine éternelle. Il est de son temps et de tous les temps.

Ainsi, dans l'effort d'un tel artiste, rien que puisse négliger l'étude. Un grand peintre existait dans le grand statuaire, et l'avenir dira que les peintures de Carpeaux, les ébauches mêmes, font honneur à la main dont elles sortirent. Elles ajoutent avec les dessins, à ce nom inscrit au livre d'or de nos gloires, un rayon de plus.

Et ce n'est certes pas sans la peine cuisante d'un regret que je salue, avant la dispersion définitive (1), cet incomparable ensemble ! Leçon magnifique du génie, dont l'atelier du boulevard Exelmans nous donnait l'éclatant résumé, et que, mieux inspirés, nos musées eussent dù revendiquer comme un bien national. Une œuvre comme celle-ci se confond avec l'àme de la France. C'est le patrimoine de tous.

\section{VICTOR MARGUERITTE.}

(1) Car voici définitirement anéanti cet Atelier du boulevard Exelmans oì M"'o Clément Carpeaux et M. Louis Carpeaux avaient jusqu'ici conservé indivis le précieux héritage paternel. De tnute cutte réunion d"œuvres uniques, plus rien ne subsiste Le vent des enchères l'aura émiettéc. On ne la verra plus reparaitre qu'au hasard des ventes futures ou au caprice des legs, ramenant au port des musées ces épaves du génie. C'est de cette façnn que le Louvre s'est déja enrichi des marbres de la princesse Mathilde. Edouard et Eruest André, du bronze de M. Beauvois, du bas-relief de Flore. L'atelier lui-meme disparait, sous ce fot de pierres qui peu ì peu s'étend, chasse d'Auteuil ses maisons vieillottes et ses derniers arbres. 



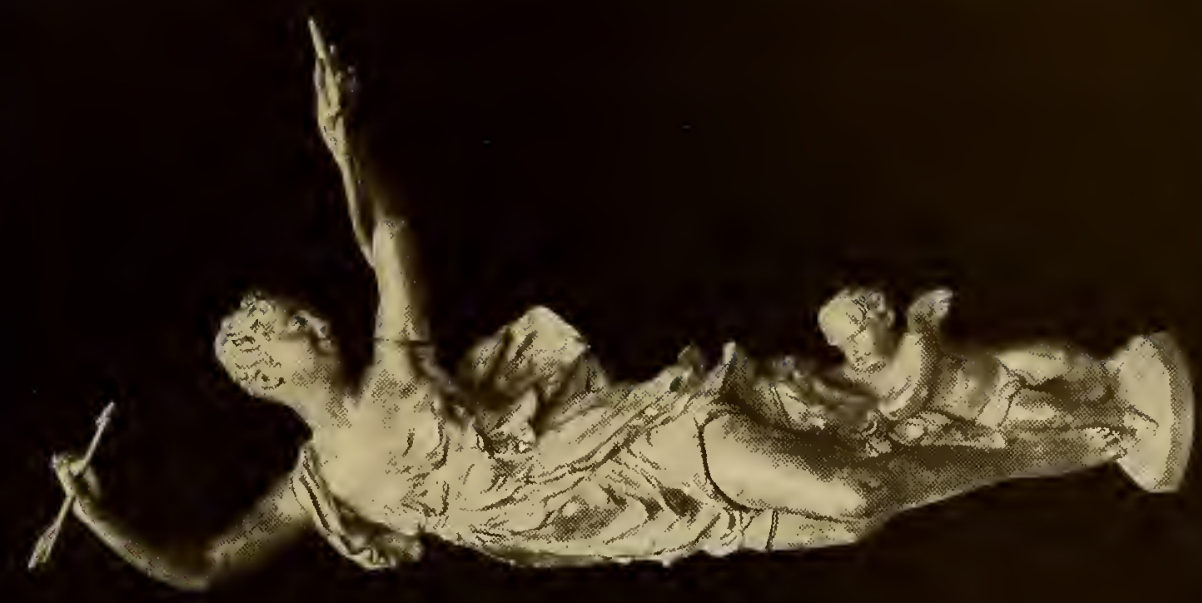

$=$

z

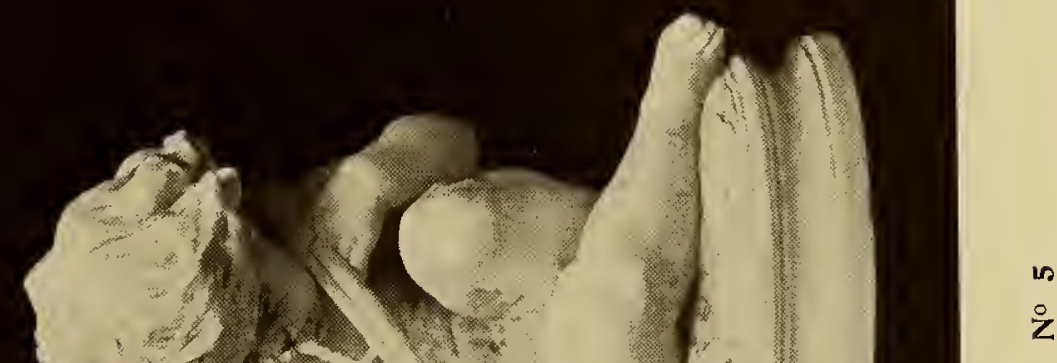

ํㅜㄹ

$\bar{z}$ 



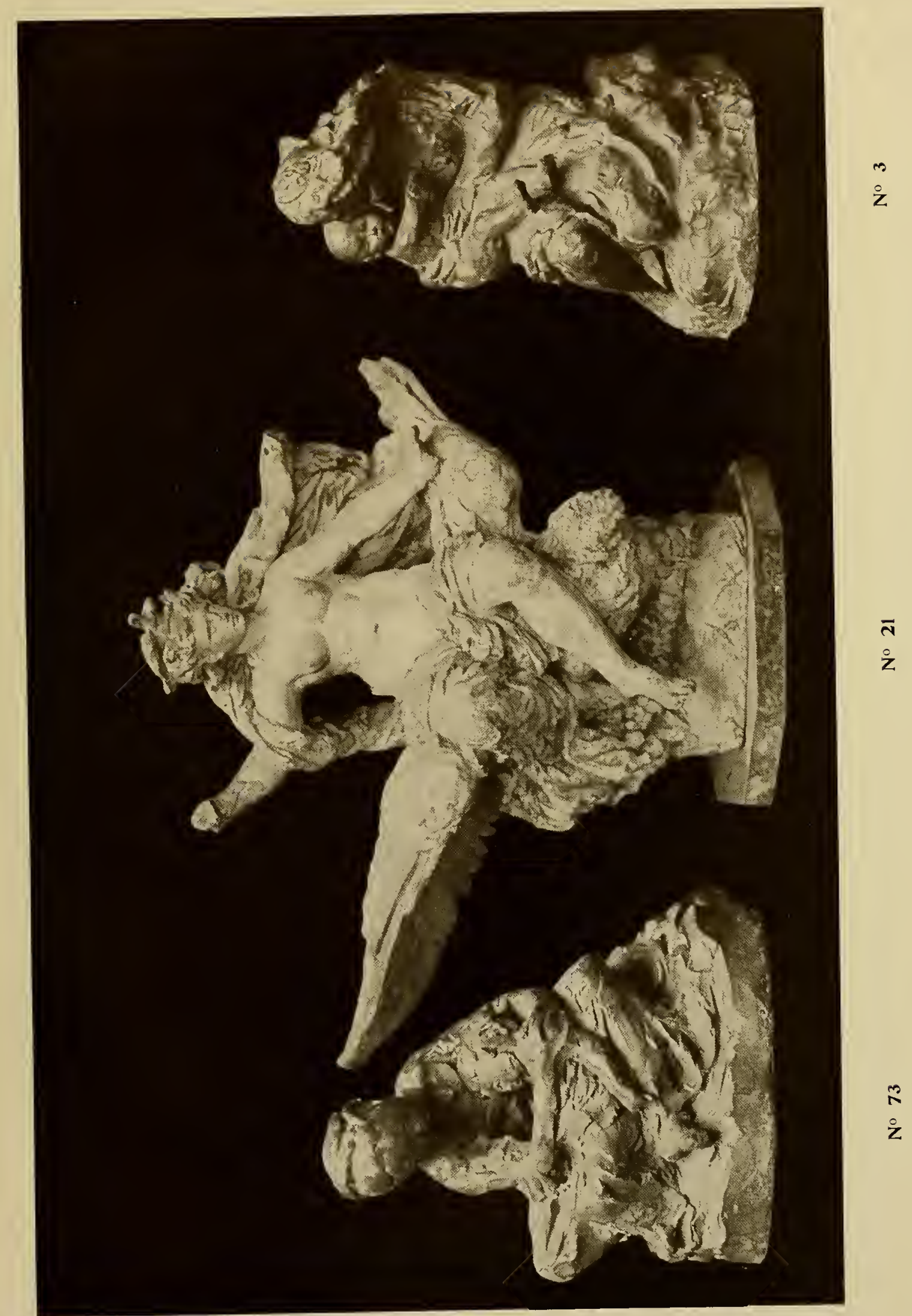





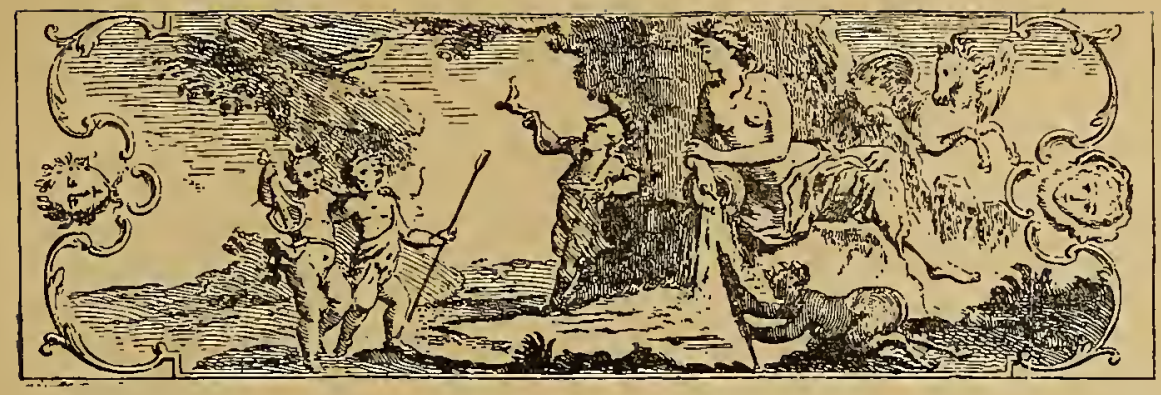

\section{DÉSIGNATION}

\section{SCULPTURES}

\section{GROUPES ET STATUETTES}

\section{1. - La Toilette.}

Modèle en bronze.

Haut., o m 69 .

Le plâtre original a figuré à la ventedu 30 mai $1913 .-\mathrm{N}{ }_{20}$.

2. - Suzanne surprise.

Terre cuite ancienne, ayant servi de modèle pour la fonte.

Haut., o m. 70 .

Le platre original et le modèle en bronz̧e ont figuré à la vente du 30 mai I 913 . - Nos 12 et I 3 .

3. - Jeune mère.

Esquisse.

Bronze d'art.

Première épreuve.

Signé du cachet de l'atelier.

Le plâtre original est au musée du Louvre.

Exposition de Liverpool, Jullet 1909.

Exposition du Jeu de Paume (Tuilertes), I9I2. - No 202. 
4. - La Ville de Valenciennes défendant la Patrie.

Modèle en bronze.

Haut., o m. 55.

Le plâtre original a figuré à la vente du 30 mai 19 13. - No 15.

5. - L'Enfant au cor. (Statuettc.)

Plâtre original.

Une des dernjères cuvres de J.-B. Carpeaux.

Le modèle bronze est entré dans une collection particulière.

Haut., o m. 30.

6. - Ugolin et ses Enfants. (Groupe.)

plàtre original.

Réduciion.

Le bronze grandeur nature est au musée du Louvre.

Haut., o m. 49 .

Une terre cuite originale, grandeur nalue, $I \mathrm{~m}$. So, af figuré à la venle du 30 mai I 9 I3. - No 2.

7. - L'Amour à la folie.

Première épreuve ayant servi à la fonte.

Signé : J.-B. Carpeaux, daté : 1860 .

Sujet tiré du groupe de la Danse.

Le modèle en bronze est entré dans une collection particulière.

- On ignore ce qu'est devenu le plìtre original.

Haur., o m. Ẽ.

8. - Daphnis et Chloé. (Groupe.)

Plàtre original.

Réduction.

Haut., o m. $7^{0}$.

Le plâtre original, grandeur nature, $1 \mathrm{~m}$. fo, a figuré à la vente du 30 mai Igr3. - $\mathrm{N}^{\circ} 4$.

9. - Daphnis et Chloé. (Groupe.)

Plàtre original.

Variante du précédent, étude avant la draperie.

Haut., om. $7^{\circ}$ 


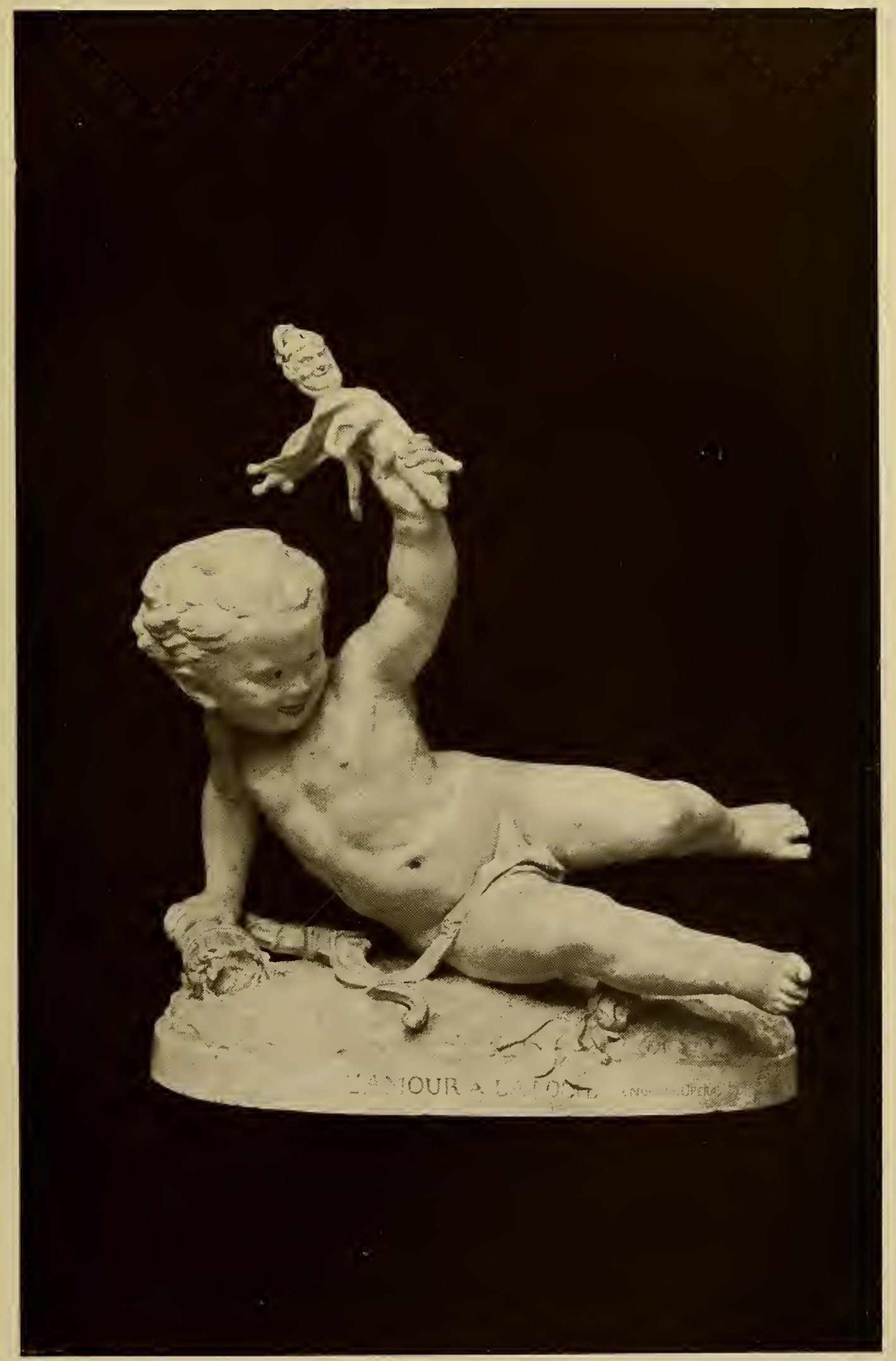





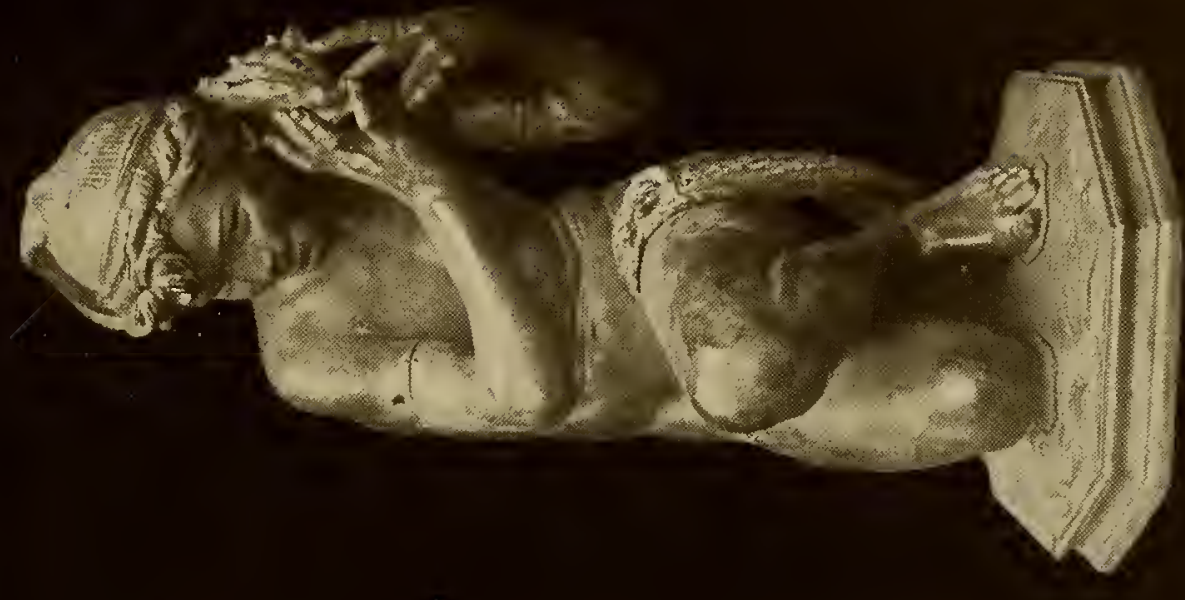

\pm
$\dot{0}$

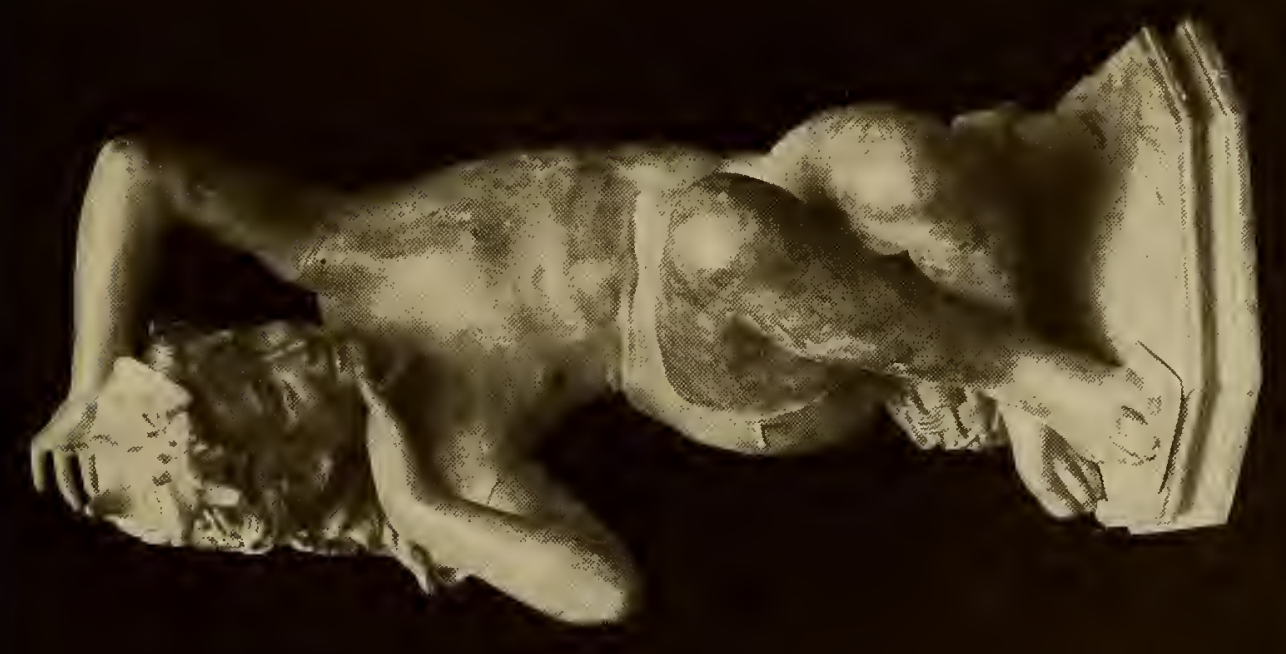



ı. - Frileuse.

Modèle en bronze.

Haut, o 111.41 .

Le plâtre original et un marbre ont figuré à la vente du 30 mai I9 I3. - Nos Io et II.

I I. - L'Amour désarmé.

- (D'après Mlle Fiocre, dans le rôle de l'A mour de Néméa.)

Modèle en bronze.

L'esquisse, plàtre original, est au musée des Arts Décoratifs.

Ce modèle bronze a été achevé par Carpeaux, d'après l'esquisse, sans nouveau plàtre original.

Haut., o m. 65.

I2. - Sainle Famille.

Maquette, plâtre original. Etude pour un groupe de La Charité destiné à l'église de la Trinité, - 1865 .

Le Louvre possède un plâtre de cette ouvre.

Signé : J.-li. Carpeautx.

Haut., o m. 36.

Exposition École Nationale des Beaux-Arts, Paris, I $894 .-\mathrm{N} \circ 3$ +o.

13. - La Jeune Fille à la coquille.

Modèle en bronze.

Haut., $1 \mathrm{~m}$.

Le plätre original de cette cuvre a figuré à la vente du 30 mai IgI3. - N'5.

14. - Le Pêchentr napolitain.

Modèle en bronze.

Le plâtre original est au musée du Louvre.

Haut., o m. go.

I5. - Génie de la Danse.

Modèle en bronze.

Haut., I m. 05.

I6. - Génie de la Danse.

Plâtre original.

Réduction.

Signé : J.-B. Carpeaux.

Haut., I m. 05 .

Le plâtre original, grandeur nature, $2 \mathrm{~m}$. 30, a figuré à la vente du 30 mai 19 I3. - No 3. 
17. - La Pêcheuse de vignots.

Modèle en bronze.

Haut., o m. 74 .

Le plâtre original et un marbre ont figuré à la vente du 30 mai 19r3. - Nos 8 et 9 .

18. - Le Marchand de poissons.

Terre cuite préparée pour la fonte.

Fragment.

Etude pour une statue dont on a perdu la trace en France.

La figure entière mesurait I m. 25 .

Haut., o m. 80 .

On voit l'œuvre figurer en bronze sur les catalogues de trois ventes faites par Carpeaux: Paris, 29 avril I $873 .-$ Bruxelles, 3 juin $I 8-3$. - Londres, ir mars $I \delta-7$.

I9. - Pêcheur napolitain.

Modèle en bronze.

Réduction.

Haut., o m. $3 \%$.

20. - Flore accroupie.

Modèle en bronze.

Le plàtre original est au musée de Copenhague.

Haut., o m. 52.

Une prenière épreuve arant servi à la fonte a figuré à la vente du 30 mai 1913 . - No 19.

21. - La France Impériale éclairant le Monde.

Étude pour la décoration du Pavillon de Flore.

Plâtre original. (Fragment.)

Haut., $\circ \mathrm{m} .80$.

22. - Le Prince Impérial an chapeau. (Statuette.)

Plâtre. 


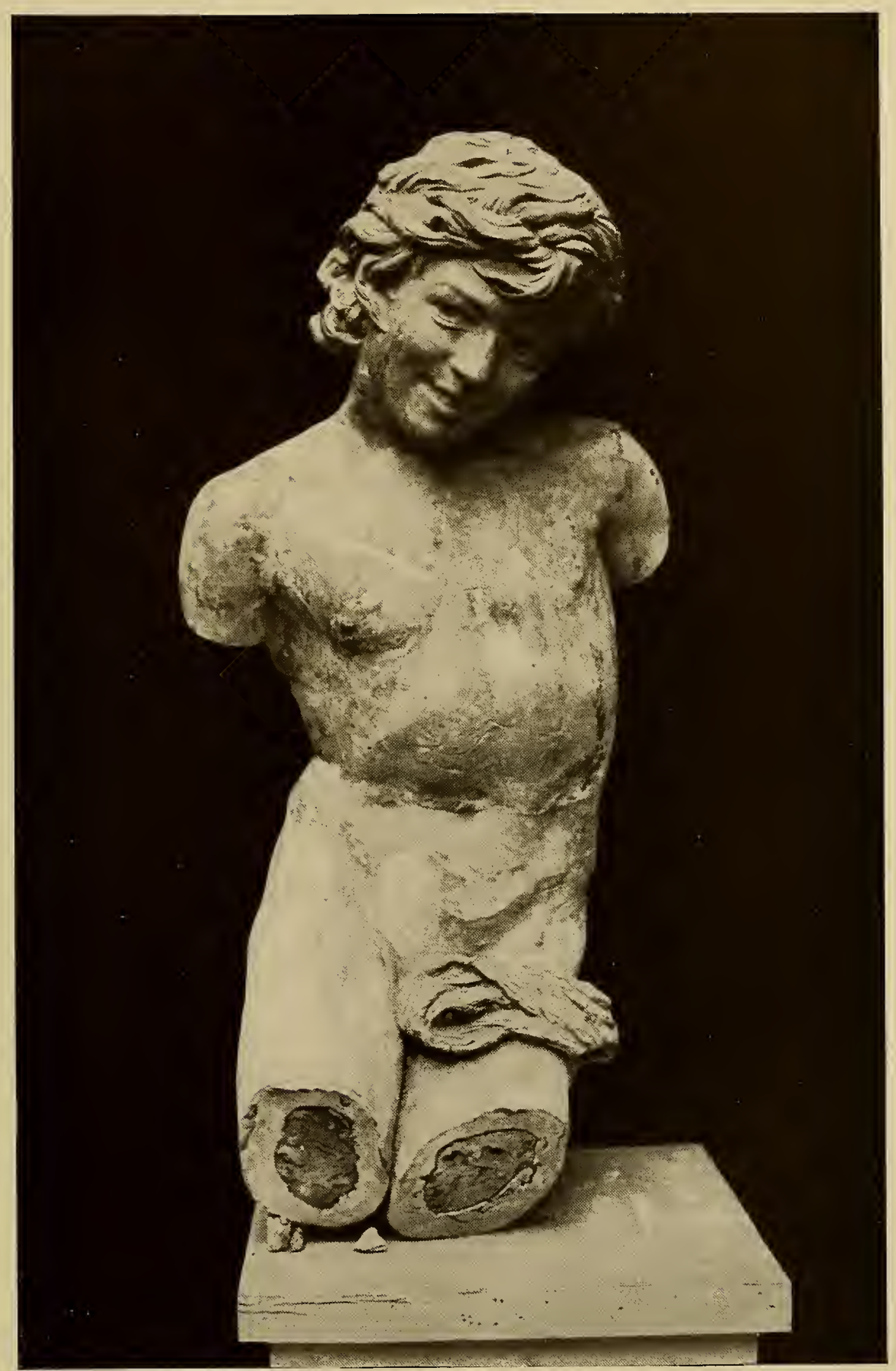





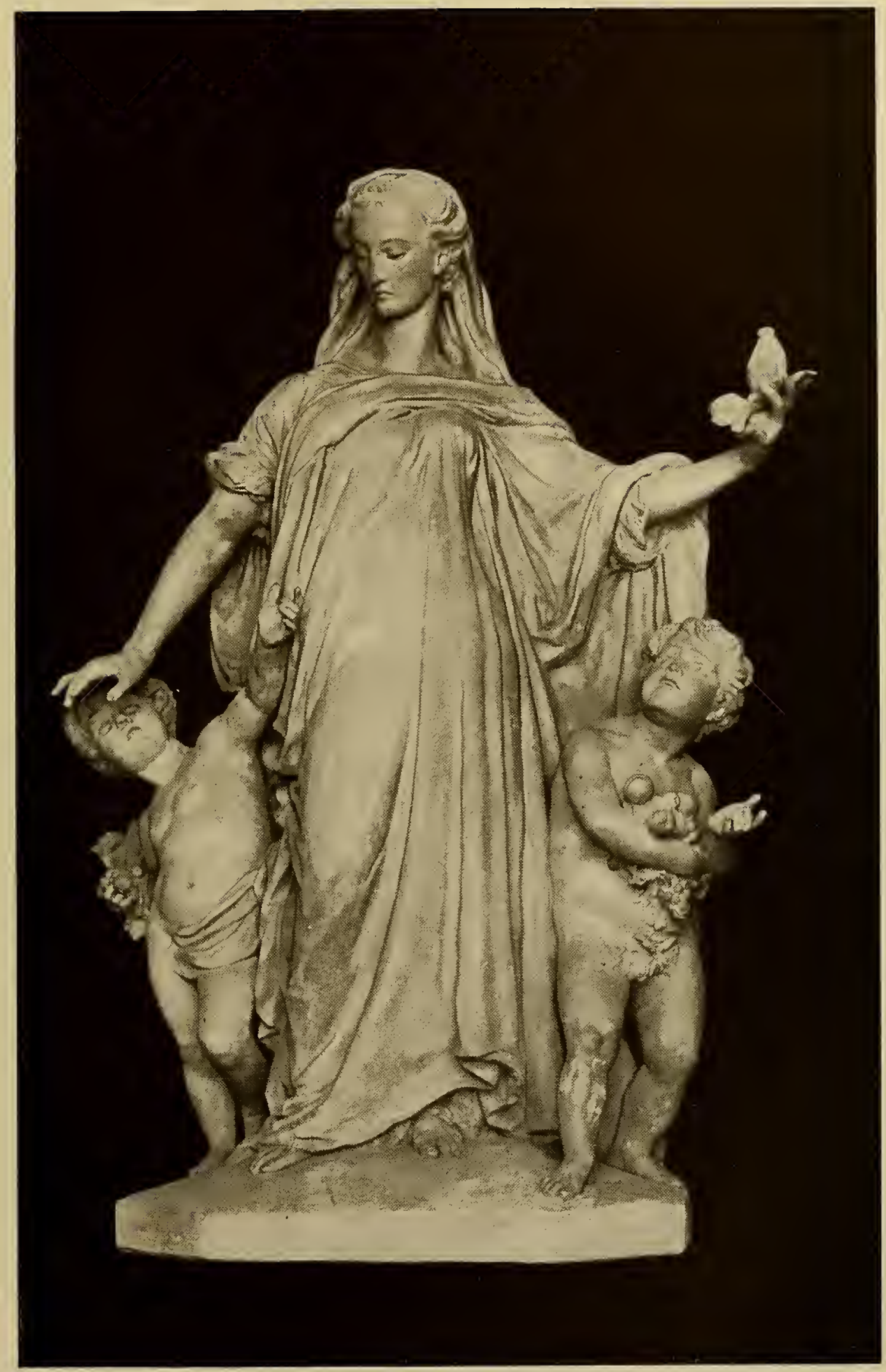





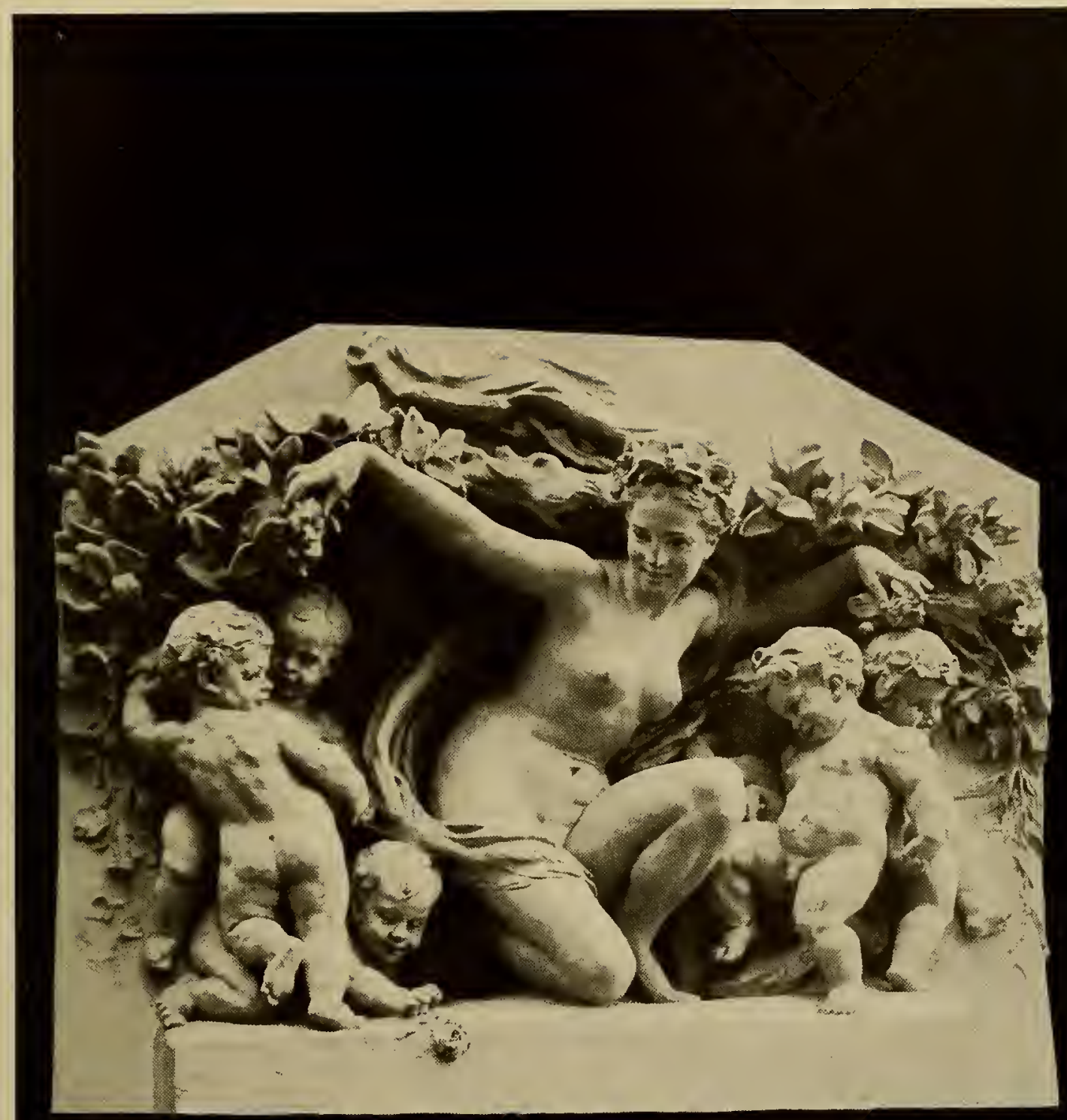



23. - La Tempérance. (Groupe.)

Terre cuite.

Signé : J.-B. Carpeaux, daté : 1869 .

Ce groupe est exécuté en pierre à l'église de la Trinité.

Le plâtre original a été brisé.

Haut., I m. 50 .

24. - Flore. (Haut-relief.)

Belle épreuve en plâtre.

Haut., I m. 45 ; larg., I m. 70.

Exposition Franco-Britannique, Londres, 1908.

Exposition Société Royale des Beaux-Arts, Bruxelles, Igog.

Exposition au Jeu de Paume (Tuileries), I 912.

\section{BUSTES}

\section{PORTRAITS, COMPOSITIONS DÉCORATIVES}

25. - Rieuse napolitaine.

Modèle en bronze.

Petite réduction.

Haut., o m. 10.

Le Rieur napolitain, même taille, a figuré à la vente du 30 mai I913, monté sur l'écritoire. - No 62 .

Les plâtres originaux ont figuré à la vente du 30 mai Igr3. Nos 34 et 35 .

26. - Étude pour le portrait du Prince Impérial.

Plâtre original.

Haut., o m. 50.

27. - Masque de l'Empereztr Napoléon III.

Moulage en plâtre, fait par Carpeaux après la mort de l'Empereur.

Haut., o m. 35 . 
28. - Rieuse napolitaine.

Modèle en bronze.

Haut., o m. 50 .

29. - Rieur napolitain.

Modèle en bronze.

Haut., o m. 50 .

3o. - P'ortrait de $M^{\mathrm{me}}$ la Duchesse de $M \ldots$

Plàtre original.

Réduction.

Le plàtre original, grandeur nature, est au musée de Copenhague.

Haut., o m. 45 .

31. - Négresse.

Plàtre original.

Réduction.

Signé : J.-B. Carpeau.x, et daté : 1868 .

On lit sur le socle: Pourquoi naîte esclave?

Haut., o m. 35.

Le plâtre original, grandeur nature, $0 \mathrm{~m}$. G4, a figuré à la vente du 30 mai 19 I3. - No 42 .

32. - Chinois.

Plâtre original.

Réduction.

Haut., o m. $3 \mathrm{I}$.

Le plâtre original, grandeur nalure, o m. 67 , a figuré à la yente du 30 mai $19 \mathrm{I} 3 .-\mathrm{No}+\mathrm{l}$.

33. - L'Espérance. (Buste avec bras.)

Plâtre original.

Etude pour une composition décorative simplifiée, dont le plàtre original est au musée de Copenhague.

Haut., o m. 60. 








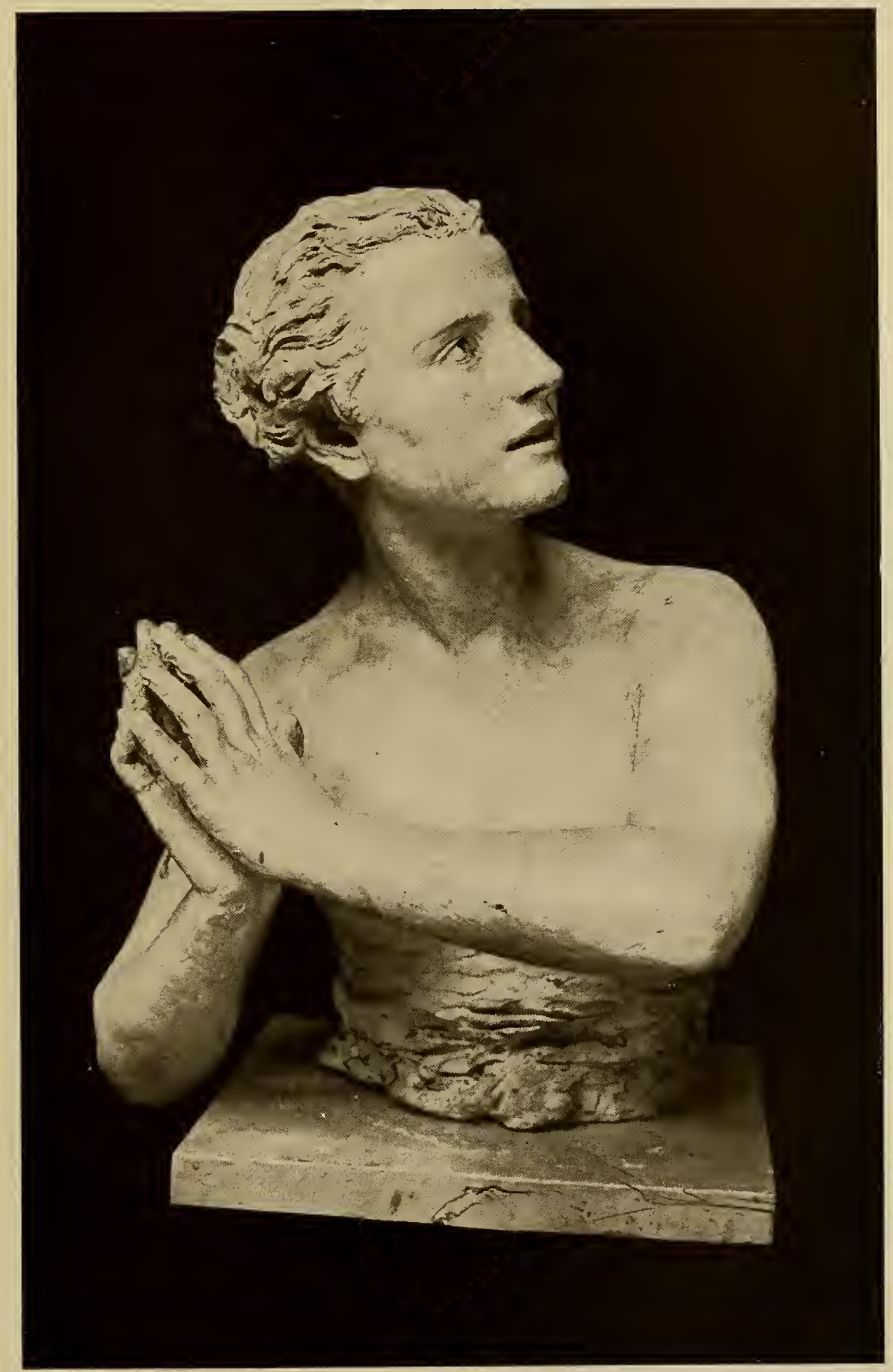



34. - Portrait de Mademoiselle F...

Plàtre original.

Réduction.

Le plâtre original, grandeur nature, est au musée du Louvre.

Haut, o m. $4^{\text {n. }}$

35. - Bacchante aux vignes. (Buste.)

Terre cuite originale.

Il n'existe pas de modèle en bronze.

Signée : $J$-B. Carpeaux, datée : 1875 .

Haut., o m. 60.

Le plâtre original a figuré à la vente du 30 mai 19 r.3. - No $3 \mathrm{I}$.

36. - La Palombelle au collier. (Buste.)

Plâtre original.

Haut., o m. 42 .

37. - Le Petit Boudeur.

Plâtre original.

Signé : J.-B. Carpeaux.

Haut., o m. 30 .

Le modèle en bronze a figuré à la vente du 30 mai rgr $3 .-$ No 36 .

38. - Tête de Faune.

Plâtre original.

Etude pour le groupe de la Danse.

Haut., o m. 34 .

Une cive perdue, épreuve unique, a figuré à la vente du 30 mai I 9 I3. - No 39.

39. - Rieur napolitain.

40. - Rieuse napolitaine.

Plâtres originaux.

Signés : Bte Carpeaux.

Haut., o m. 50. 
41. - Portrait d'Alexandre Dumas fils.

Plâtre original.

Réduction.

On lit sur le socle: All' Huomo penserioso Alexandre Dumas fis. - Suo Amico : Bte Carpeaux, 1873.

Le plàtre original, grandeur nature, est au musée du Louvre. Le marbre a été légué par $\mathrm{A}$. Dumas à la Comédie-Française.

Haut., o m. 47 .

42. - Bacchante, les yeux baissés. (Buste.)

Plàtre original. .

Éude pour le groupe de la Danse.

Une cire perdue, épreuve unique, a figuré à la yente du 30 mai IgI3. - No 37 .

43. - L’Espérance. (Buste.)

Terre cuite originale.

Le plàtre original est au musée de Copenhague.

II n'existe pas de modèle en bronze.

Haut., o m. 53.

44. - Bacchante criant. (Buste.)

Plàtre original.

Étude pour le groupe de la Danse.

Haut., o m. 35.

Une cire perdue, épreuve unique, a figuré à la vente du 30 mai Ig 13. - No 38.

45. - Bacchante aut $x$ roses.

Première épreuve préparée pour la fonte.

Le plâtre original est au musée de Copenhague.

Haut., o m. 63.

46. - Le Génie de la Danse. (Buste.)

Plâtre. Belle épreuve du temps de Carpeaux.

Variante du génie du groupe de la Danse.

Signé : Ble Carpeaux.

Le plàtre original est entré dans une collection particulière.

Haut., o m. 62. 


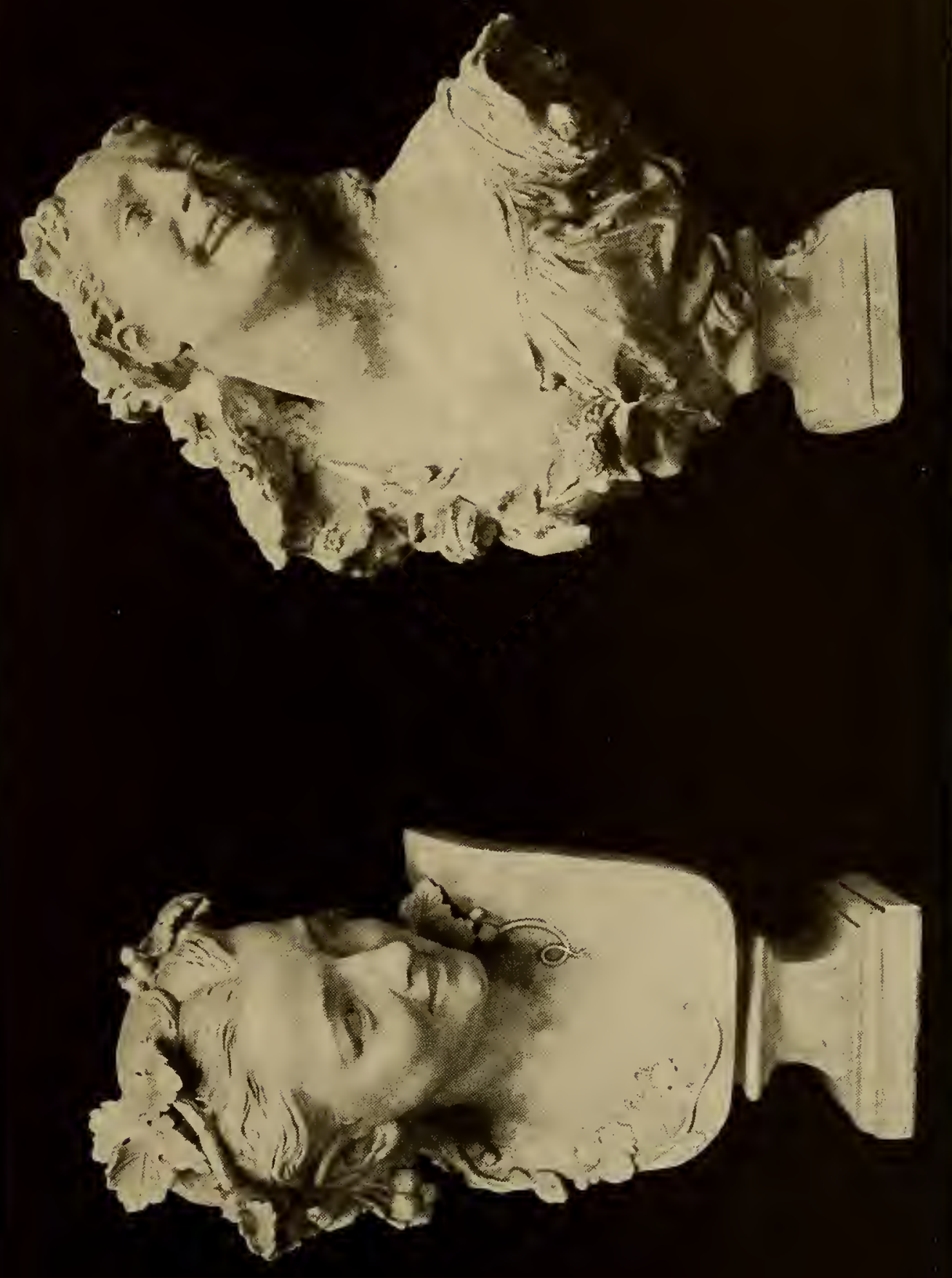



47. - Rieur napolitain.

48. - Rieuse napolitaine.

Modèles en bronze.

Haut., o m. 27.

49. - Portrait du marquis de Piennes. (Buste.)

Plâtre original.

On lit sur le socle : A son ami de Piennes. - Bte Carpeaux, Rome I 862.

Haut., o m. 54 .

Exposition École Nationale des Beaux-Arts, Paris, $1894 .-$ No 413.

5o. - Espiègle.

Plâtre original.

Signé : Be Carpeaux.

Haut., o m. 53.

Exposition École Nalionale des Beaux-Arts, Paris, 1894 . No 390.

Le modèle en broñ̨e a figuré à la vente du 30 mai I 9 1.3. - No 30 .

5ı. - Portrait de M. Vatdremer.

Plâtre original.

On lit sur le socle : $B^{i e}$ Carpeaux, à son ami Vaudremer. Rome $185 \mathrm{~g}$.

Haut., o m. 48.

Exposition Societé Royale des Beaux-Arts, Bruxelbes, 1909.

52. - Chinois.

Modèle en bronze, réduction.

Étude pour l'Asie, de la fontaine du Luxembourg.

Haut., o m. 35.

Le modèle en bronże, grandeur nature, a été acquis à l'Exposition de Vienne, 1903 . 
53. - Négresse.

Modèle en bronze, réduction.

Étude pour l'Afrique, de la fontaine du Luxembourg.

Haut., o m. 35 .

Le modèle en bronze, grandeur nature, a été acquis à l'Exposition de Vienne, I 903.

54. - Bacchante aux roses.

Modèle en bronze.

Haut., o m. $€ 3$.

55. - Portrait de Napoléon III. (Buste.)

Plàtre original, réduction.

Signé : J.-B. Carpeaux, daté : 13 janvier 1873 .

Le plâtre original grandeur nature est au Louvre.

Haut., o m. 35.

Une terre cuite originale a figuré à la vente du 30 mai $1913 .-$ No54.

56. - Bacchante aux roses.

Modèle en bronze.

Réduction.

Haut., o m. 36 .

57. - Buste de Femme avec broche. (Portrait.)

Plâtre original.

Haut., 0 m. 54.

58. - Portrait de M. Chardon-Lagache.

Plâtre original.

Signé : J.-B. Carpeaux.

Exposition École Nationale des Beaux-Arts, Paris, 1894. No $42 \mathrm{~S}$.

59. - Le Printemps.

Modèle en bronze.

Variante de la tète de Flore du bas-relief des Tuileries.

Le plàtre original est au musée de Copenhague.

Haut., o m, 45. 


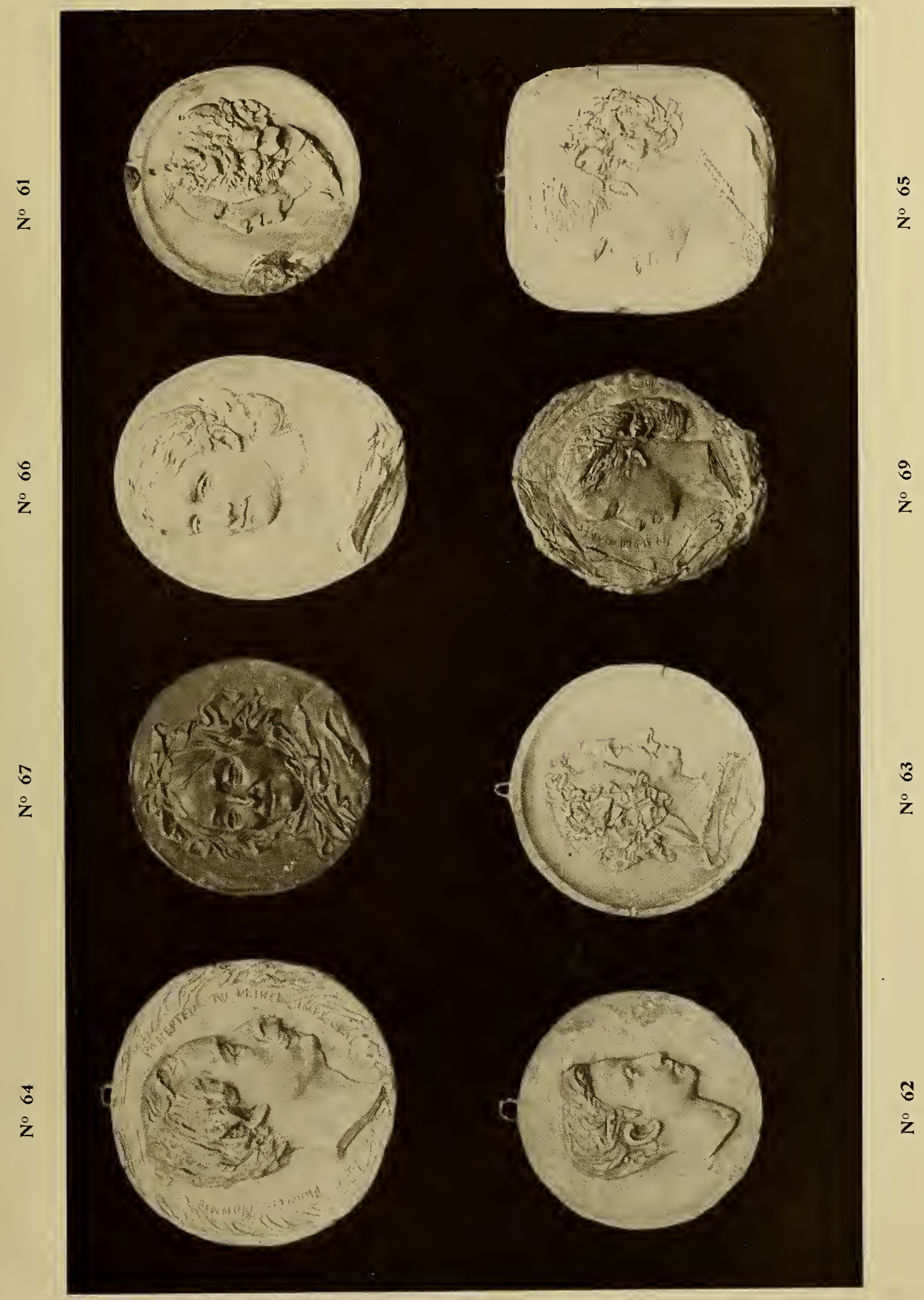





\section{MÉDAILLONS, ÉCRITOIRE}

6o. - Monsieur X...

Plàtre original.

Signature et dédicace : $A$ mon ami...

Salon d'Automne (Rétrospective Carpeaux), I g07. $-\mathrm{N} \cdot 31$.

61. - Madame X. (Profil.)

Plàtre original.

62. - Le Prince impérial. (Profil.)

Plàtre original.

63. - Femme àgée. (Profil.)

Plàtre original.

Signé : J.-B. Carpeaux.

Exposition Centennale, Igoo. - No 1517.

Exposition au Jeu de Paume (Tuileries), 1912.- No 185.

64. - Francis Monnier, précepteur du Prince impérial.

Plâtre original.

Signé : J.-B. Carpeaux, daté : I 865.

Exposition au Jeu de Paume (Tuileries), 1912.- No 184 .

65. - Mademoiselle Bouvet, lectrice de l'Impératrice.

(Profil.)

Plàtre original.

Exposilion au Jeu de Paume (Tuileries), 19 $92 .-$ No 187. 
65. - Madame Mac-Nab, née comtesse d'Anglars. (Trois-quarts.)

Première épreuve.

Signé : J.-B. Carpeaux, daté : 1864 .

Exposition au Jeu de Paume (Tuileries), I9 I2. - No 183.

67. - Madame Defly.

Médaillon de face.

Modèle en bronze.

Signé : J.-B. Carpeaur, daté : Jannier 1863.

Connu à tort comme portrait de la mère de Carpeaux.

Exposition Centennale, $1900 .-$ No 1516.

Exposition au Jeu de Paume (Tuileries), 1912. - № 182.

68. - Monsieur Reynal.(De profil.)

Plàtre original.

Bas-relief octogonal portant la dédicace: Hommage d'amitié offert par l'auteur à M. Reynal, directeur du musée de Lille.

Signé : J.-B. Carpeaux.

Exposition au Jeu de Paume (Tuileries), 1912. - No 189.

69. - Portrait de l'Impératrice Eugénie.

Terre cuite originale, profil.

Euvre du Prince impérial.

Signé : Louis Napoléon 1V. "l'Impératrice des Français, I 2 juin $x$ S6... (5?) 》

Exposition de Bagatelle.

70. $-\dot{E}$ critoire. (Composition décorative.)

Première épreuve préparée pour la fonte.

On ignore ce qu'est devenu le Plâtre original.

Haut., o m. I 5 ; larg,, o m. 28.

Le modèle broñ̨e a figuré à la vente du 30 mai r g I3. - No 62 . 


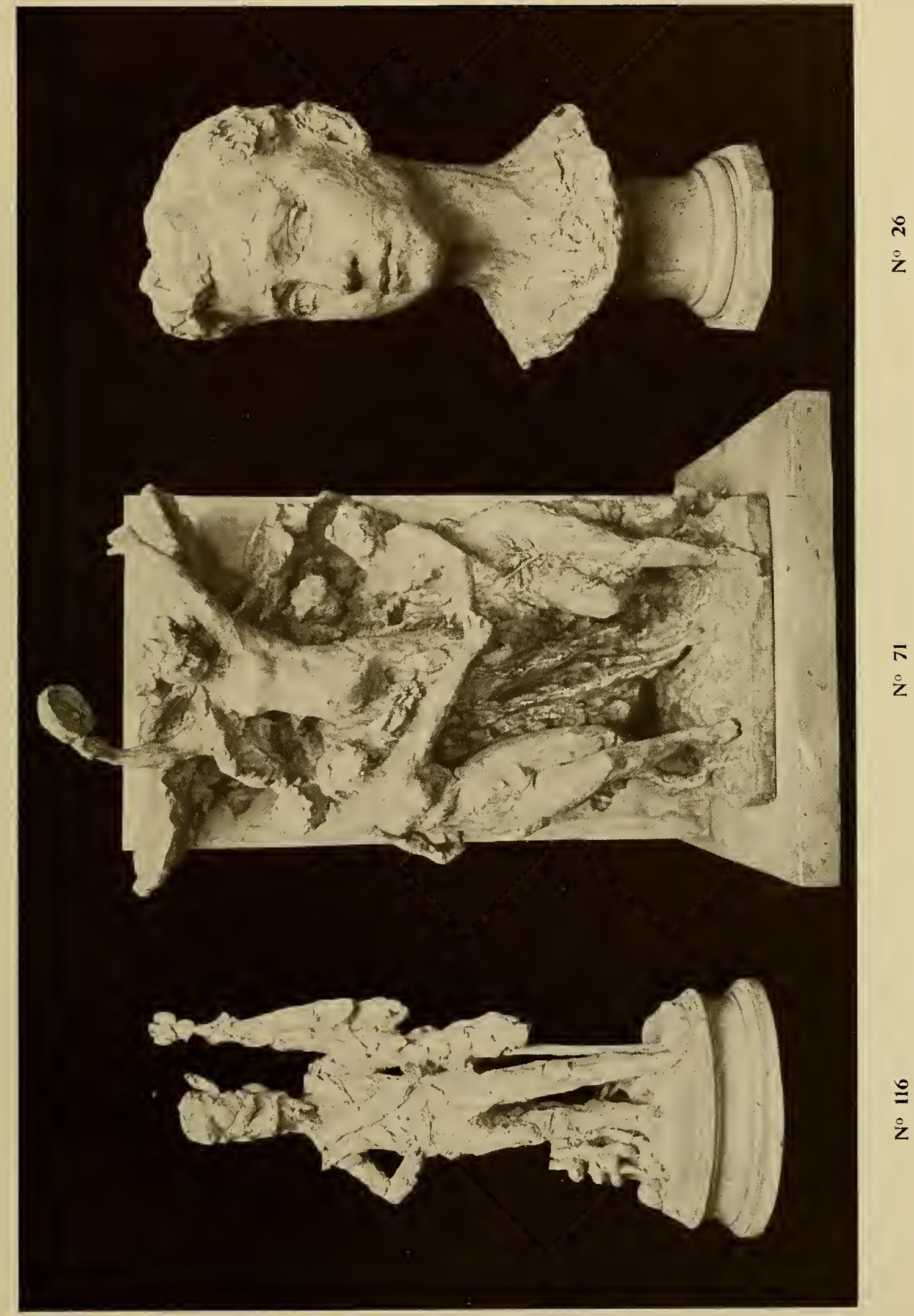





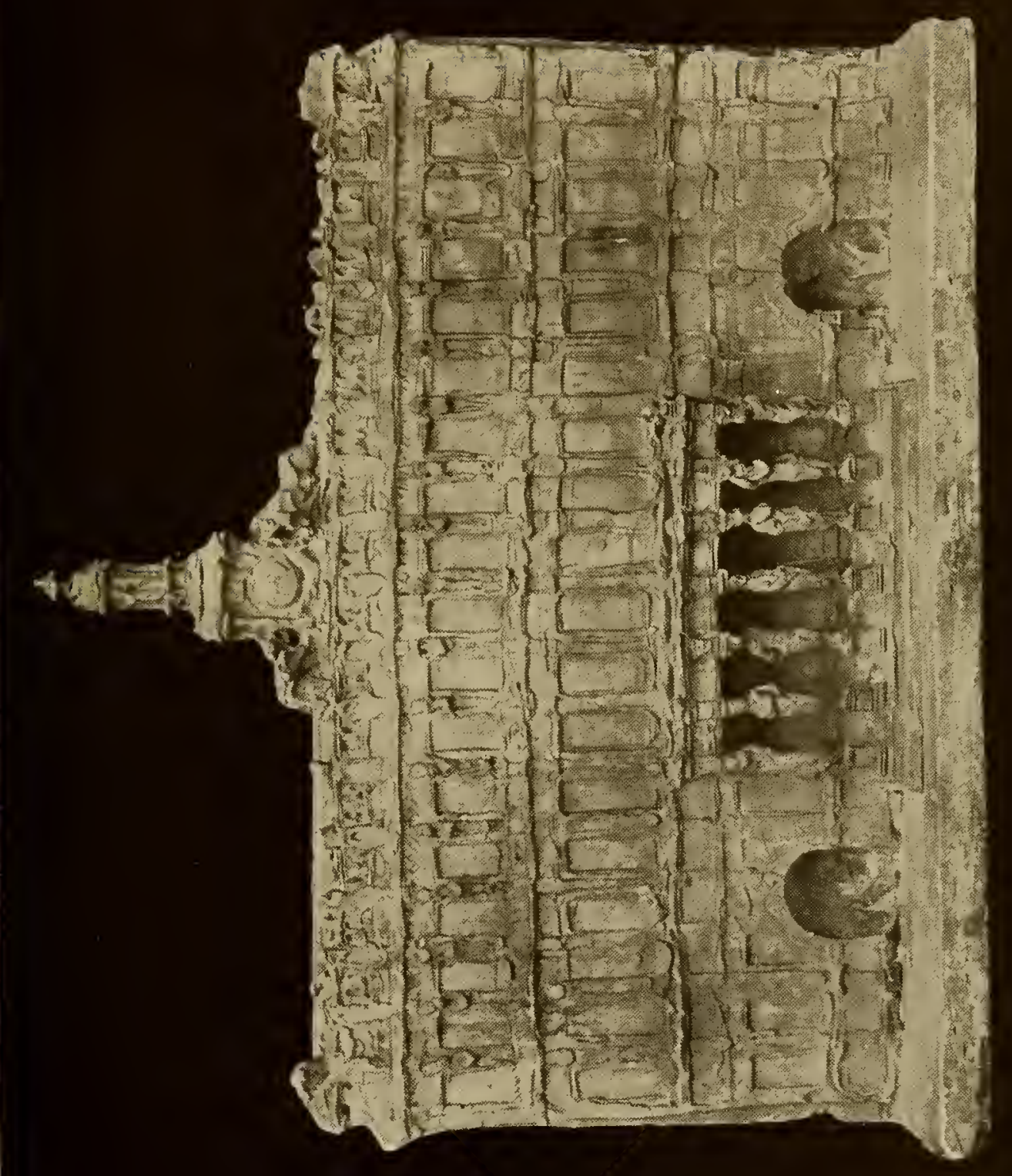





\section{ESQUISSES}

71. - La Danse. (Groupe.)

Maquette plâtre, épreuve.

Le plâtre original est au musée du Louvre.

Haut., o m. 55.

72. - Projet de décoration pour la façade de l'Hôtel de Ville de Valenciennes. (Bas-relief.)

Plàtre original.

Haut., o m. 75 ; larg. o m. 83.

Salon d'Automne (Rétrospective Carpeaux), rg07. - No 34 .

Exposition au Jeu de Paume (Tuileric's), rgI2. - No 227.

73. - Maternité : L'Enfant malade. (Groupe.)

Bronze à cire perdue, deuxième épreuve.

Portant le cachet : cire perdue, J.-B. Carpeaux.

Haut., o m. $2 \mathbf{1}$.

Exposition Société Royale des Beaux-Arts, Bruxelles, I 909.

Exposition au Jeu de Paume (Tuileries), I9 I 2.- No 200.

74. - Paul et Virginie. (Groupe.)

Plâtre original.

Esquisse.

Une variante de cette composition se trouve au musée du Louvre.

Haut., o m. 38 .

Salon d'Automine (Rétrospective Carpeaux), 1907.- No 44 .

75. - Ève tentée.

Fragment.

Maquette terre cuite.

Haut., o m. 07.

Le plâtre original de cette ouvre a figuré à la vente du 30 mai I 9 I 3.

Le modèle en bronze est entré dans une collection particulière. 
76. - Extase.

Maquette en terre cuite.

Haut, $\cap \mathrm{m}, 22$.

Exposition École Nationale des Beaux-Arts, Paris. - No 368.

Exposition au Jeu de Paume (Tuileries), I9I2. - No 204.

77. - Les Quatre parties du Monde. (Fontaine du Luxembourg.) (Groupe.)

Plàtre original.

Esquisse.

Variante du plàtre que possède le musée du Louvre.

Haut., ก m. 55.

Exposition École Nationale des Beaux-Arts, Paris, I894. N" 344.

Salon d'Automne (Rétrospective Carpeaux), r907. - No 47.

Exposilion au Jeu de Paume (Tuileries), Ig I2. - No 220.

78. - Négresse. (Fragment)

Terre non cuite.

Etude pour la fontaine du Luxembourg.

Haut., o m. 15.

79. - Les Quatre parties du Monde. (Fontaine du Luxembourg.) (Groupe.)

Maquette en terre non cuite.

Haut., o m. 48 .

8o. - Saint Sébastien.

Maquette terre cuite.

Projet pour une statue.

Haut., o m. \5.

8ı. - Confidence. (Groupe.)

Maquette terre cuite.

Haut., o m. 16. 


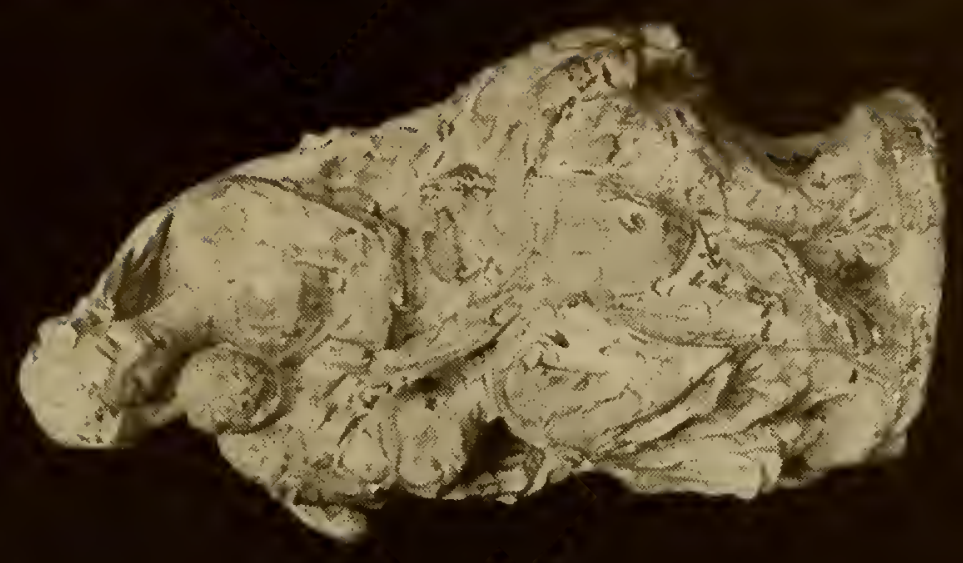

$\stackrel{\text { I }}{\text { Z }}$

$\left(\frac{19}{12}\right.$

ำ

之 

82. - Pieta. (Groupe.)

Maquette terre cuite.

Haut., o m. 26 .

Exposition École Nationale des Beaulx-Arts, Paris, , 89 t.- №350.

83. - Le Guerrier.

Maquette terre cuite.

Haut., o m. 16 .

Exposition au Jéu de Paume (Tuileries), 19I2. - Sans numéro.

84. - Femme couchée.

Maquette en terre non cuite.

Haut., o m, o6.

85. - La Toilette.

Maquette terre cuite.

Itaut., o m. 16.

86. - La Douleur.

Maquette terre cuite.

Haut., o m. u\&.

87. - Réconciliation. (Groupe.)

Maquette terre cuite.

Haut. o m. I 5 .

Exposition au Jeu de Paume (Tuileries), I g Iz. - Sans numéro.

88. - Amour maternel. (Groupe.)

Maquette cire.

Haut., o m. 15.

Exposition École Nationale des Beaux-Arts, Paris, 1897. No 356. 


\section{9. - La Musique et la Tragédie. (Groupe.)}

Maquette terre cuite.

Première pensée du groupe que Carpeaux devait exéculer pour l'Opéra.

Le Louvre possède le plâtre original d'une maquette du même sujet; dimensions plus grandes.

Haut., o m. 21.

90. - Trait-d'union. (Groupe.)

Cire perdue, première épreuve.

Haut., o m. 20.

Exposition à la New Gallery, Londres, I gog.

Exposition Société Royale des Beaux-Arts, Bruxelles, rgog.

91. - L'Attente.

Maquette terre cuite.

Haut., o m. 16.

92. - Jeune mère jouant avec son enfant. (Groupe.)

Maquette terre cuite.

Haut., O m. 22.

Exposition École nationale des Beaux-Arts, Paris, $189+$ - No 354 .

Salon d'automne (Rétrospective Carpeaux), 1907. - No 46 .

93. - Felmme assise méditant.

Plâtre original.

Esquisse.

Haut., o m. 25 .

94. - Groupe poutr la fontaine de l'Observatoire.

Maquette terre cuite.

Variante de plusieurs projets connus. 


\section{5. - Jeune Fille.}

Maquette terre cuite.

Étude pour la Jeune fille à la coquille.

Haut., o m. 20.

Salon d'automne (Rétrospective Carpeatix), $1907 .-\mathrm{No} 40$.

Exposition au Jeu de Paume (Tuileries), I9I2. - No 206.

\section{6. - Rêveuse.}

Maquette terre cuite.

Haut., o m. 17.

Exposition École nationale des Beaux-Arts, Paris, 1894 . No 352 .

Exposition au Jeu de Paume (Tuileries), Ig I 2. - No 205.

97. - Jeanne d'Arc.

Maquette terre cuite.

Haut., o m. 10.

\section{8. - La Tempérance.}

Petite maquette terre cuite.

Projet pour le monument de l'église de la Trinité.

Hauı., o m. 1 .

\section{9. - Le Désespoir.}

Maquette terre cuite.

$$
\text { Haut., o m. } 16 .
$$

Exposition École nationale des Beaux-Arts, Paris, $189+$. No 370 .

I0o. - Suzanne surprise. (Maquette.)

Plâtre original.

Étude pour l'œuvre du même nom qui a figuré dans un état différent à la vente du 30 mai i 913. 
101. - Vierge morte. (Projet pour une Ophélie.)

Maquette terre cuite.

Haut., o m. 06.

Exposition École Nationale des Beaux-Arts, Paris, 1894. No 364 .

102. - Consolation. (Groupe.)

Maquette terre cuite.

Haut., o m. 23.

103. - Rotrou. (Buste.)

Cire.

IIaut., o m. I7.

Exposition École Nationale des Beaux-Arts, Paris, I $894 .-$ No $37+$.

104. - Amour maternel. (Groupe.)

Maquette terre cuite.

Haut., o m. 16.

Exposition École Nationale des Beaux-Arts, Paris, I $894 .-$ No 355.

Exposition au Jeu de Paume (Tuileries), I g г 2. - No 209.

I05. - Accablement.

Maquette terre cuite.

Haut., 0 m. 3o.

Exposition École Nationale des Beaux-Arts, Paris, I894. No 359 .

Exposition au Jeu de Paume (Tuileries), $1912 .-$ No 208.

106. - Décoration pour le fronton du Pavillon de Flore. Trois plàtres originaux:

La France éclairant le monde.

La Science.

L'Agriculture.

Signés : Be Carpeaux.

Une fonte d'art deces troispièces a figuré à la vente du 30 mai I 913. - No $6 \mathbf{I}$. 
107. - Taureau couché.

Terre non cuite.

Etude pour la décoration du Pavillon de Flore.

Haut., o m. 25.

Exposition au Jeu de Paume (Tuileries), rg т2. - № 2 I 3.

108. - Trait-d'union. (Groupe.)

Maquette terre cuite.

Haut., o m. 20.

Salon d'Automne (Rétrospective Carpeaux), rgo7.- № 4 I.

rog. - Pieta. (Groupe.)

Maquette terre cuite.

Haut., o m. 2 r.

Exposition École Nationale des Beaux-Arts, Paris, I894. No 349 .

Salon d'Aulomne (Rétrospective Carpeaux), rgo $7 .-N^{\circ} 39$.

I о. - Suzanne surprise.

Maquette terre cuite.

Étude pour l'œuvre du même titre.

Haut., o m. r.

111. - Lutteurs. (Groupe.)

Maquette terre cuite.

Haut., o m. I 7 .

I1 2. - Petit Génie. (Haut-relief.)

Fragment pour la décoration du Pavillon de Flore.

Esquisse.

Plâtre original.

Haut., o m. 2.

I13. - Projet pour une statue représentant la ville de Valenciennes.

Maquette.

Plâtre original teinté. 
II4. - Femme endormie.

Maquette terre cuite.

Haut., o m. I7.

Exposition all Jeu de Paume (Tuileries), I 9 I 2. - No 203.

I 5. - Imploration.

Maquette terre cuite.

Haut., o m. 26.

116. - Le Grenadier après la bataille.

Esquisse, plâtre original par S. A. le Prince Impérial, élève de Carpeaux.

Signé : Napoléon IV le 6 février I 864.

Haut., o m. 40 . 


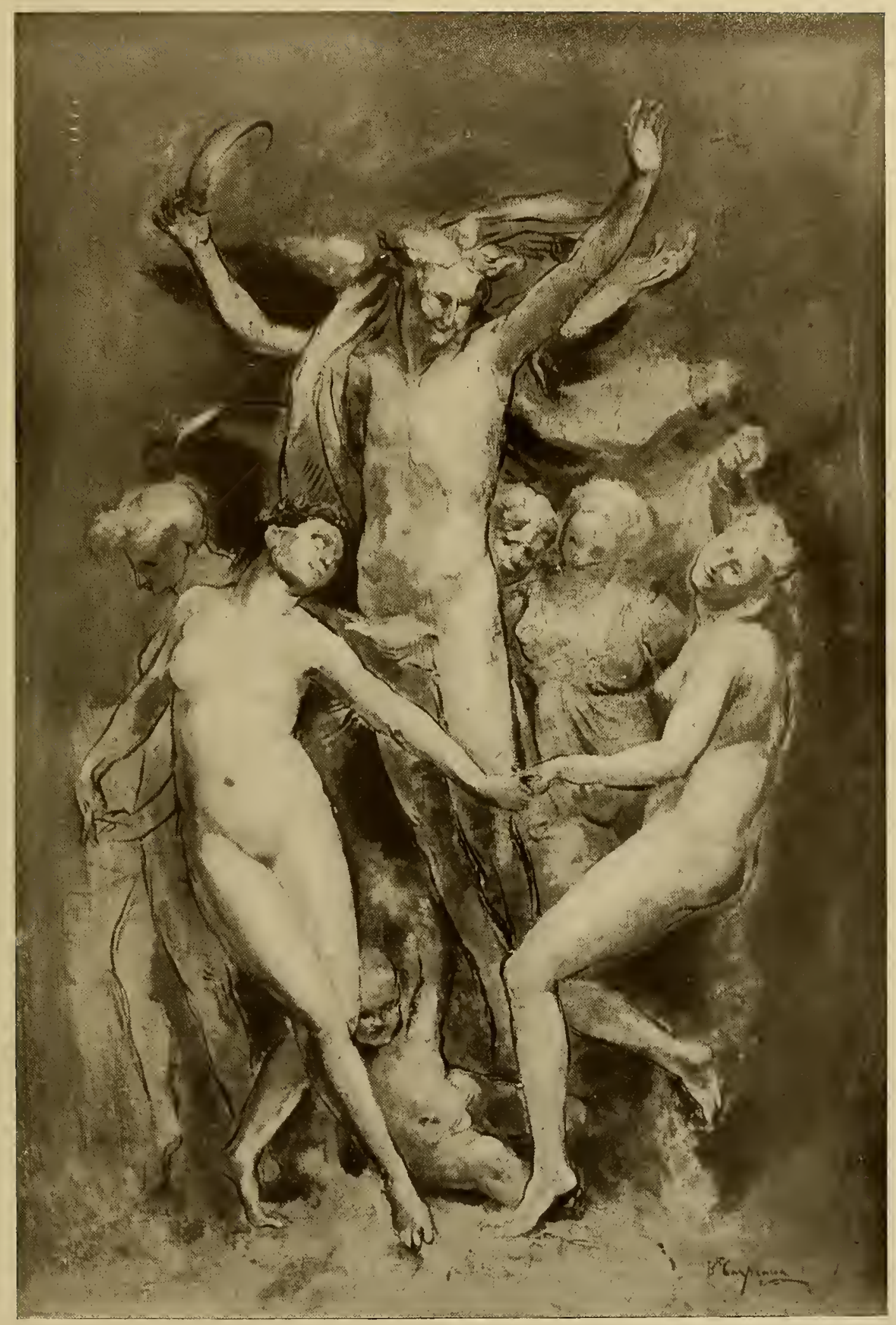





\section{TABLEAUX PAR CARPEAUX}

117. - Chislehurrst, Camden Place. (Paysage.)

Signé à droite.

Peinture sur carton.

Hant., o m. 36 ; larg, o m. 42.

Exposition École Nationale des Beaux-Arts, Paris, $1894 .-\mathrm{N}^{\circ} 4^{2}$.

Exposition Maison d'Art, Bruxelles, $1896 .-\mathrm{N}^{\circ} 19$.

118. - S. A. I. le Prince Impérial distribuant les récompenses à l'Exposition Universelle, Paris, 1867.

Signé à droite.

Toile.

Haut, o m. 38 ; larg., o m. $4^{5}$.

Exposition École Nationale des Beaux-Arts, Paris, $r S_{94}-$ No 83.

Exposition Maison d'Art, Bruxelles, I896. - No 30.

119. - La Danse.

Composition peinte par l'artiste d'après le grand groupe exécuté en terre glaise.

Peinture traitée en grisaille, sauf pour la femme représentée à gauche du groupe, reprise d'après le modèle vivant.

Signé à droite.

Panneau.

Haut., o m. 56 ; larg., o m. 38.

Exposition École Nationale des,Beaux-Arts, Paris, $1894 .-$ No 2. Salon d'Automne (Rétrospective Carpeaux), 1907. - No 74 . Exposition au Jeu de Paume (Tuileries), I 9 I2. - No 228. 
120. - Portrait d'Homme.

Signé à droite.

Toile.

Haut., o m. to ; larg., o m. 30.

Exposition École Nationale des Beaux-Arts, Paris, $1894 .-\mathrm{N} 02 \mathrm{I}$. Exposition Maison d'Art, Bruxelles, 1896 . - No 8.

I2I. - Buste de Femme.

A gauche, cachet de cire aux initiales de Carpeaux.

Toile.

Ilaut., o m. 46 ; larg., o m. 38 .

Exposition École Nationale des Beaux-Arts, Paris, I894. No I1 2.

I22. - Descente de croix.

Grisaille.

Signé à droite.

Panneau.

Haut., O m. $5 \mathrm{r}$; larg., $0 \mathrm{~m} .39 \mathrm{r} / 2$.

Exposilion École nationale des Beaux-Arts, Paris, I $\$ 94$, no I I , sous le titre: "Ensevelissement".

Salon d'Aulomne (Rétrospective Carpeaux), I907. - No57.

Exposition au Jeu de Paume (Tuileries), I $912 . \div \mathrm{N}^{0} 25$ t.

123. - Copie d'après une peinture de Michel-Ange à la chapelle Sixtine (Rome.)

Signé à droite.

Peinture sur carton.

Haut., o m. 68; larg., o m. 52.

Exposition École nationale des Beaux-Arts, Paris, $1894 .-$ No 67.

124. - Tête d'Italienne.

Signé à droite.

Toile sur carton.

Haut,, o m. 27; larg., o m. 22.

Exposition École Nationale des Beaux-Arts, Paris, I $89 t$, no $10 \mathrm{r}$, sous le titre: Femme mauresque.

Salon d'Automne (Rétrospective Carpeaux), I907. - No 59.

Exposition au Jeu de Paume (Tuileries), I $912 .-$ No 258. 


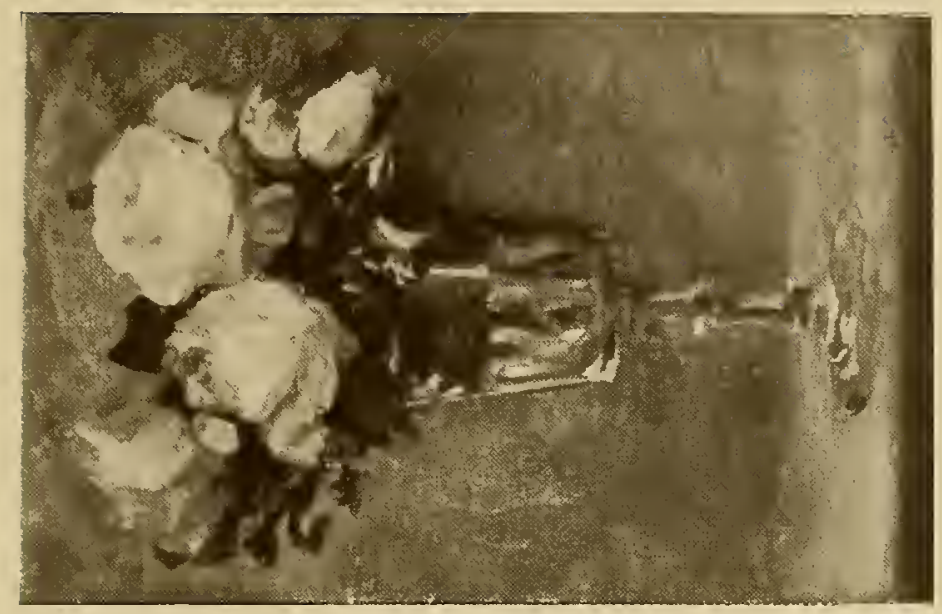

$\frac{\Xi}{Z}$

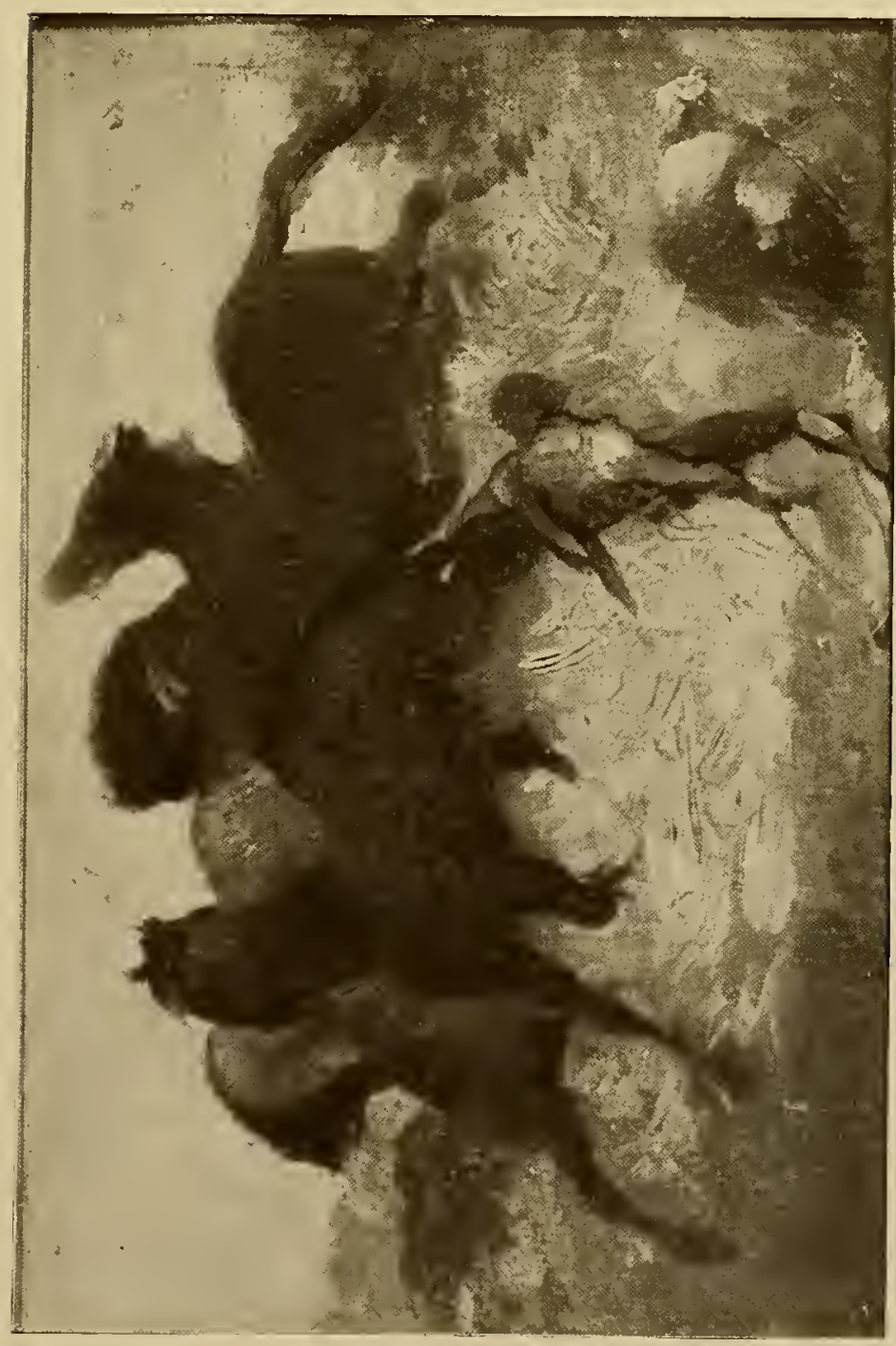

$\frac{\check{2}}{2}$ 

125. - Épisode du siège de Paris (1870): départ des troupes par temps de brouillard.

Signé à droite.

Toile.

Haut., o m. 34; larg., o m. 55.

Exposition École Nationale des Beaux-Arts, Paris, I894. No 15 .

Exposition Maison d'art, Bruxelles, I 896. - No 40.

Exposition au Jeu de Paume (Tuileries), I 9 I2. - No 246.

126. -- Mise au tombeau.

Signé à droite.

Toile sur carton.

Haut., o m. 23; Iarg., o m. $30 \mathrm{~s} / 2$.

Exposition École Nalionale des Beaux-Arts, Paris, 1804 , sous le titre : Christ mort. - No 33.

Exposition Maison d'Art, Bruxelles, 1896 . - No 16.

127. - Roses dans un verre.

Signé à droite.

Toile.

Haut., o m. $32 \mathrm{r} / 2$; long., o m. 22.

Exposition École Nationale des Beaux-Arts, Paris, 1894 . N०64.

Exposition Maison d'Art, Bruxelles, I896.- No 2.4.

Salon d'Automne (Rétrospective Carpeaux), 1907. - No 60.

Exposition au Jeu de Paume (Tuileries), 19 12. - No 238.

128. - Coucher de soleil.

Paysage.

Signé à droite.

Toile.

Haut., o m. 35; larg., o m. 45.

Exposition École Nationale des Beaux-Arts, Paris, I 894 . $\mathrm{N} \cdot 82$.

Expostion Maison d'Art, Bruxelles, 1896 , sous le titre : Paysage, crépuscule. - No 34 .

Exposition au Jeu de Paume (Tuileries), 1912 . - No 237. 
129. - Tête d'Homme.

Traces de signature à droite.

Toile sur carton.

Haut., o m. $33 \mathrm{~J} / 2$; larg., o m. $27 \mathrm{I} / 2$.

Exposition École Nationale des Beaux-Arts, Paris, 1894 .

I30. - Chevaux dans la campagne romaine.

Signé à gauche.

Pcinture sur carton.

Haut., o m. 23; Jarg., o m. 35 .

Exposition École Nationale des Beaux-Arts, Paris, 1894 , sous le titre: Courses de chevaux sauvages au Corso. - No 70.

Exposition Maison d'Art, Bruxelles, 1896. - No 25.

131. - Paysage italien.

Signé à droite.

Etude faite par Carpeaux lors de son séjour à Rome.

Toile.

Haut., o m. 32 ; larg., o m. 36

Exposition École Nationale des Beaux-Arts, Paris, r\$94. No ıog.

Exposition au Jeu de Paume (Tuileries), IgI2. - $\mathrm{N}_{2} 32$.

I32. - Descente de Croix, d'après Rubens.

A gauche, cachet de cire aux initiales de Carpeaux.

Peinture sur carton.

Haut., o m. 41 ; larg., o m. 24.

Exposition École Nationale des Beaux-Arts, Paris, 1894 . No 84 .

Exposition Maison d'Art, Bruxelles, ז $896 .-$ No 3 г. 

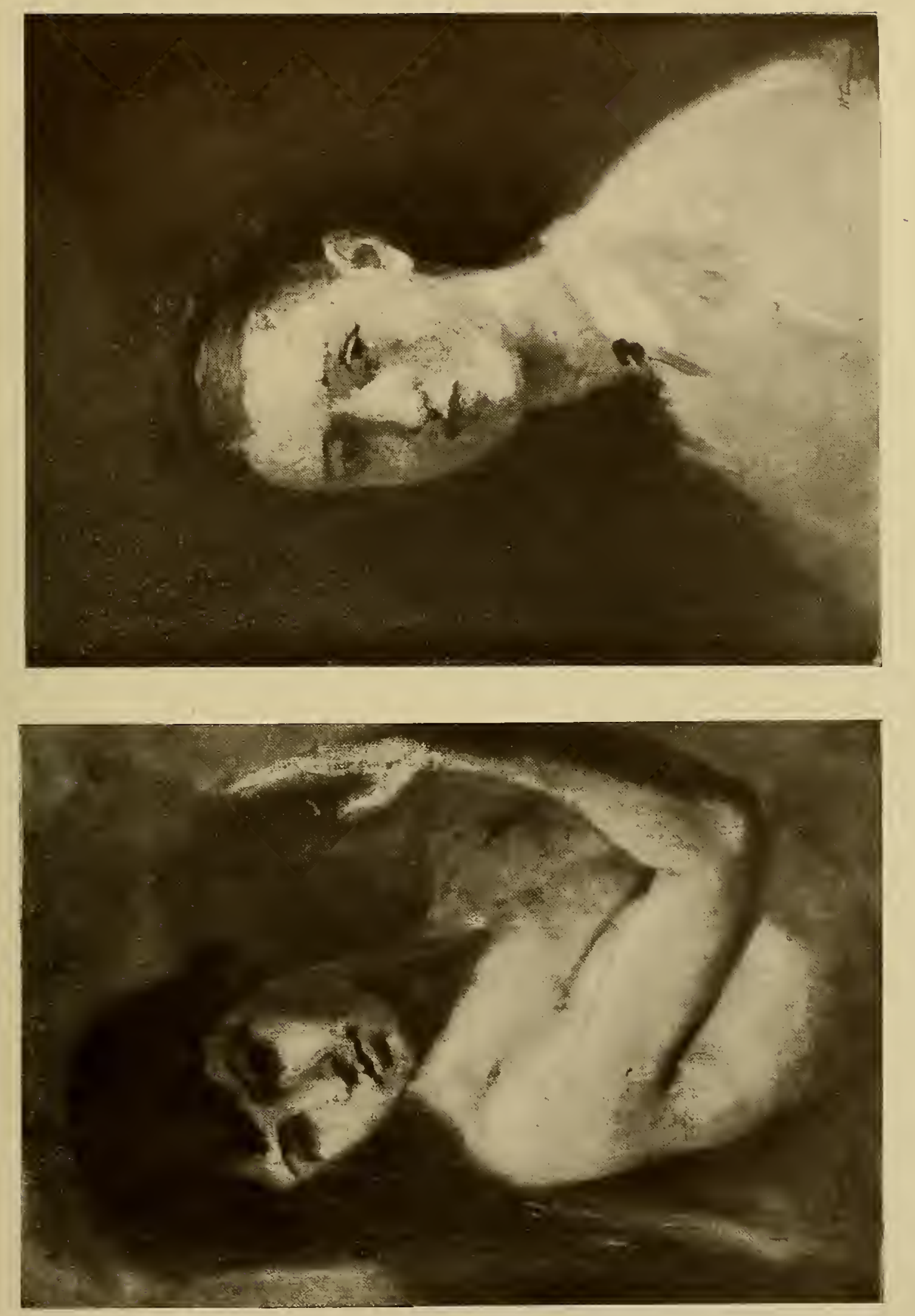

$\frac{\overrightarrow{2}}{2}$ 

133. - Portrait de Mlle Barbe de $M^{\star \star \star *}$.

Signé à droite.

Toile sur carton.

Haut., o m. 52 ; larg., o m. 40

Exposition Ecole Nxtionale des Beaux-Arts, Paris, I894. No 40.

Exposition au Jeu de Paume (Tuileries), I 9 I 2. - No 244.

I34. - Saint Jean.

Signé à gauche.

Toile sur carton.

Haut, o m. 56 ; larg., o m. 38.

Exposition au Jeu de Paume (Tuileries), I 9 I 2. - No 245.

135. - Deux compositions sur toile:

I $^{\circ}$ La Mort d'Ananie.

Peinture en grisaille.

A gauche, cachet de cire aux initiales de Carpeaux.

$2^{\circ}$ La Prédication.

Haut., o m. 3n; larg., o m. 50.

Étude à l'encre et au crayon.

Haut., o m. 3o; larg., o m. 50.

136. - Mor Darboy dans sa prison.

Signé à droite.

Toile.

Haut., o m. 57; larg., o. m. 68.

Exposition École Nationale des Beaux-Arts, Paris, I 894 , sous le titre : "Mor Darbor au milieu de ses geôliers. " - No 19.

137. - Le Mariage chrétien.

A gauche, cachet de cire aux initiales de Carpeaux.

Toile.

Haut., o m. 38 ; larg., o m. 45 . 


\section{I38. - Vénus, Mercure et Cupidon.}

Copie d'après le tableau du Corrège, de la National Gallery, et exécutée à Londres en 1872 .

Signé dans le haut à droite: $B^{\text {te }}$ Carpeaux d'après le Corrège. Toile.

$$
\text { Haut., I m }+5 \text {; larg., o m. go. }
$$

Exposition École Nationale des Beautx-Arts, Paris, $1894 .-\mathrm{N}^{\circ} 5 \mathrm{I}$. Sxlon d'Automne (Rétrospective Carpeaux), 1907.- No 62 . Exposition au Jeu de Paume (Tuileries), I 9 I 2.

I39. - La Confidence.

Grisaille d'après le projet d'un groupe actuellement au musée de Valenciennes.

A gauche, cachet de cire aux initiales de Carpeaux.

Toile.

Haut., I m. 17 ; larg., o m. 90.

Exposition au Jeu de Paume (Tuileries), Ig I 2.- Hors catalogue.

I41). - Un Bal au Palais des Tuileries, I867.

Dans la salle des Maréchaux, on aperçoit à droite, sur l'estrade: l'Empereur, l'Impératrice, la Princesse Mathilde et le Roi des Belges. Devant les souverains, les couples enlacés se livrent au plaisir de la danse.

Signé à droite et daté : 1868 .

Toile.

$$
\text { Haut., o m. } 60 \text {; larg., o m. } 73 \text {. }
$$

Exposition École Nationale des Beaux-Arts, Paris, I 894.--No 30. Exposition au Jeu de Paume (Tuileries), 19I2. - No 229.

\section{1. - Portrait de M. Charlery de la Masselière.}

Signé à gauche.

Panneau.

Exposition École Nationale des Beaux-Arts, Paris, $1894 .-$ No 35.

Exposition Maison d'Art, Bruxelles, I896. - No 17.

Salon d'Automne (Rétrospective Carpeaux), 1907. - No 56. 


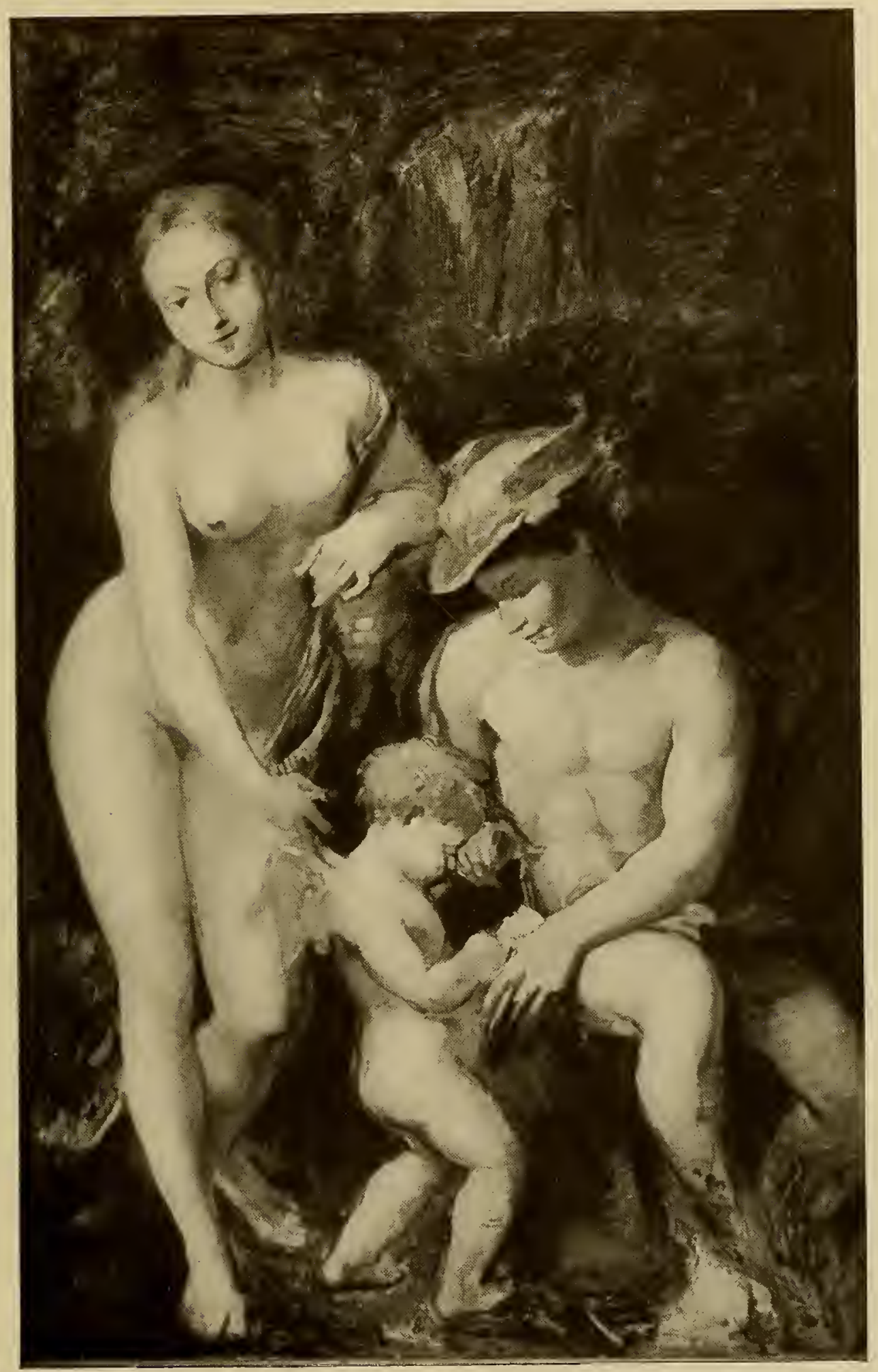





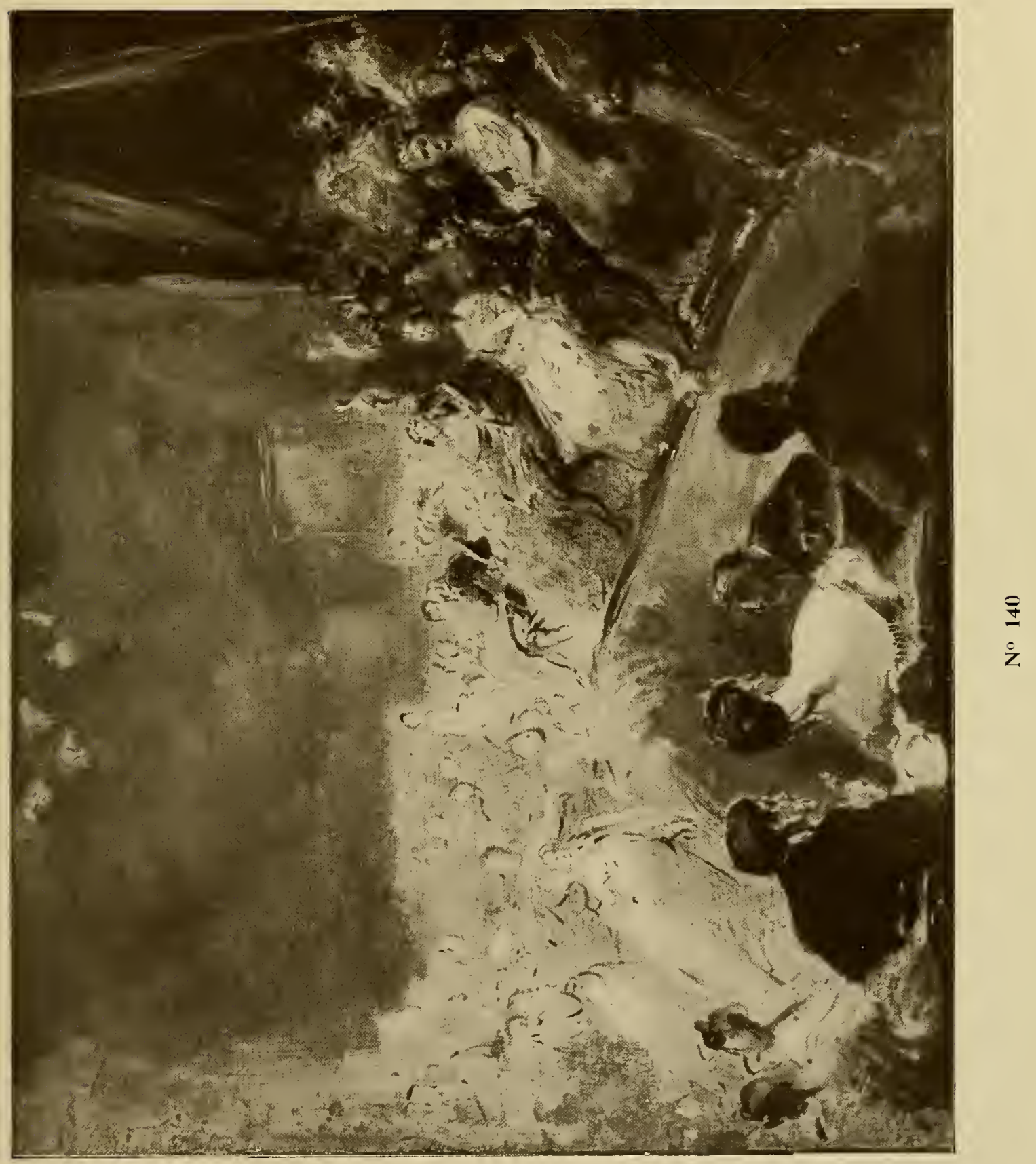



142. - Vue de Londres: la Tamise et les ponts.

A gauche, cachet de cire aux initiales de Carpeaux.

Toile.

Haut., o m. 41 ; larg., o m. 32.

143. - Coucher de soleii; paysage.

Signé à gauche.

Toile sur carton.

Haut., o m. 27; larg., o m. $411 / 2$.

144. - Le Retour du Calvaire.

A gauche, cachet de cire aux initiales de Carpeaux.

Toile sur carton.

Haut., o m. 54 ; lar $5 ., 0 \mathrm{~m}+t$.

145. - Un Martyr chrétien. .

Signé à droite.

Toile.

Haut., o m 41 ; larg, o m. 32.

Exposition École Nationale des Beaux-Arts, Paris, 189 4.-No81. Exposition Maison d'Art, Bruxelles, I896. - No 33.

146. - Paysage au soleil couchant.

A gauche, cachet de cire aux initiales de Carpeaux.

Toile sur carton.

Haut., o m. I 8 ; larg., o m 26 .

147. - Les Apôtres en présence du Saint-Esprit.

A gauche, cachet de cire aux initiales de Carpeaux.

Toile.

Haut., o m.40; larg., o m. 32.

148. - Le Christ et les saintes Femmes.

Signé à droite.

Toile.

Haut., o m. $32 \mathrm{r} / 2$; larg., o $\mathrm{m} 24$.

Exposition École Nationale des Beaux-Arts, Paris, $189+, \mathrm{n}^{\prime \prime} 3$ I, sous le titre de : Mise au tombeau". 
I49. - Mer deferlant.

Panneau.

Signé à droite.

I50. - Pont de pierre sur un cours d'eau.

Signé à gauche.

Peinture sur carton.

Haut., o m. I7; larg., o m. 28 .

Exposition Ecole Nationale des Beaux-Arts, Paris, $189+$, no I lo, sous le titre : "Paysage avec ponl".

Exposition au Jeu de Paume (Tuileries), I9I2. - No $24 \mathrm{I}$.

151. - Tête de Femme.

A gauche, l'inscription : "Bravo."

A droite, cachet de cire aux initiales de Carpeaux.

Toile.

Haut., o m. 33 ; larg., o m. 24 .

152. - Site montagneux.

Signé à droite.

Toile sur panneau.

I53. - Portrait de l'artiste.

Panneau.

A gauche, cachet de cire aux initiales de l'artiste.

Haut, o m. 32; larg., o m. 29.

154. - Falaises bretomes.

Signé à gauche.

Toile.

Haut., o m. 37; larg., o m. 59.

Exposition École|Nationale des Beau.r-Arts, Paris, I894.No 28.

Exposition Maison d'Art, Bruxelles, I $\$ 96$. - No 14.

155. - Etude. 


\section{DESSINS PAR CARPEAUX}

156. - Épisode du siège de Paris.

Dessin à la sépia.

Haut, o m.86; larg., o m. 66.

Exposition École Nationale des Beaux-Arts, Paris, I 894 , où ce dessin était exposé avec les tableaux. - No 58.

157. -- Apparition.

Signé à droite.

Dessin au crayon noir, rehaussé de blanc.

Exposition École Nationale des Beaux-Arts, Paris, I 894 . No 234 .

158. - Pieta.

Dessin au crayon noir et à la plume, sur toile.

Exposition École Nationale des Beaux-Arts, Paris, I 894 , sous le titre : "Mater Dolorosa ". - No 274.

159. - Étude d'après le Jugement dernier. (Michel-Ange.)

Dessin au crayon rehaussé.

Sanguine.

160. - Le Siège de Paris, I871. - Les Ambulances.

Signé à droite et daté : $I 8_{71}$.

Dessin rehaussé de pastel.

Exposition École Nationale des Beaux-Arts, Paris, I894. No 283.

161. - Le Siège de Paris, 1871 .

Signé à droite.

Dessin à la plume.

Exposition École Nationale des Beaux-Arts, Paris, I8y4. No 260. 
162. - Pièce en batterie. (Siège de Paris, 187 I.)

Dessin à la plume, sur panneau.

Exposition École Nationale des Beaur. Arts, Paris, IS94. No $26 \mathrm{I}$.

163. - Les Enfants de Carpeaux, dormant.

Dessin au crayon noir, signé.

Exposition Centennale, Paris, Igoo. - No 779.

Exposition École Nationale des Beaux-Arts, Paris, I894. No I5 T.

Salon d'Automne (Rétrospective Carpeaux), I907.- No 65.

E.vposition au Jeu de Paume (Tuileries), I I I2.- No 273.

164. - L'Attentat de Berẽousski.

Préparation pour la toile du Louvre.

Dessin à la plume, sur toile.

165. - Femme coucliée.

Signé à droite.

Dessin au crayon noir rehaussé de blanc.

Exposition École Nationale des Beaux-Arts, Paris, I\$94.No 3 r 8.

Exposition Centemale I9oo, sous le titre: "Femme nue". $\mathrm{N}^{0} 78 \mathrm{~T}$.

Salon d'Automne (Rétrospective Carpeau.r), I907. - № 93.

Exposition au Jeu de Paume (Tuileries), I9I2.-No 29 .

166. - $1^{\circ}$ Buste de Jeune Femme.

$2^{\circ}$ Tête d'Homme.

$3^{\circ}$ Jenne Fille assise.

Trois dessins au crayon noir, dont deux rehaussés de blanc.

167. - Portrait de Jeune Femme en toilette de bal.

Dessin au crayon noir, rehaussé de blanc, avec annotations: "chez la Princesse Mathilde, le I I mai, jour de ma naissance."

Exposition École Nationale des Beaux-Arts, Paris, 1894.No 200.

Exposition Maison d'Art, Bruxelles, I 896. - № 60.

Salon d'Automne (Rétrospective Carpeaux), I907. - No 88.

Exposition au Jeu de Paume"(Tuileries), I 9 I 2. - No 27 I.

A figuré à plusieurs expositions sous le titre: "Chez la Princesse Mathilde, " 

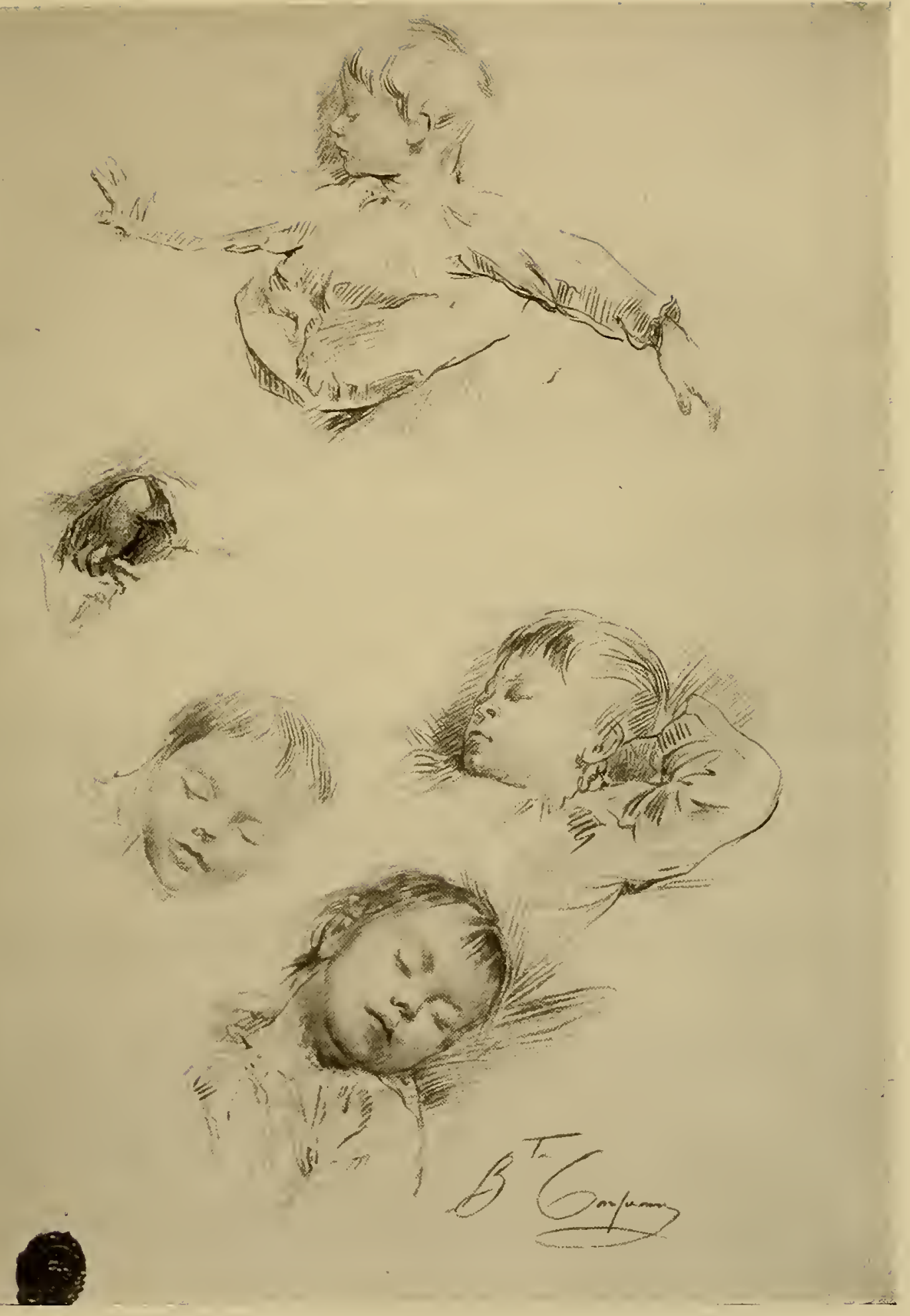

No 163 



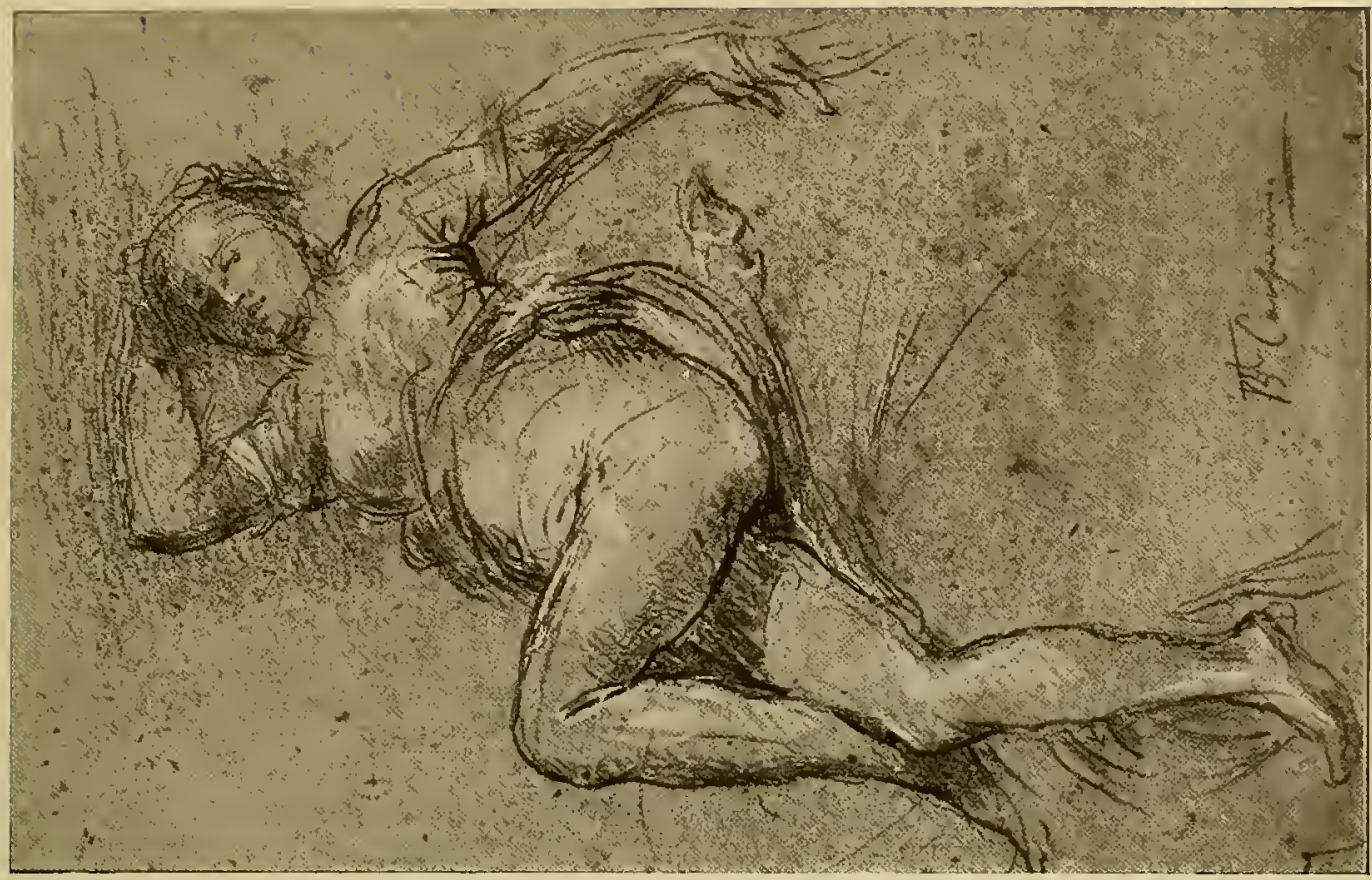

옹

₹

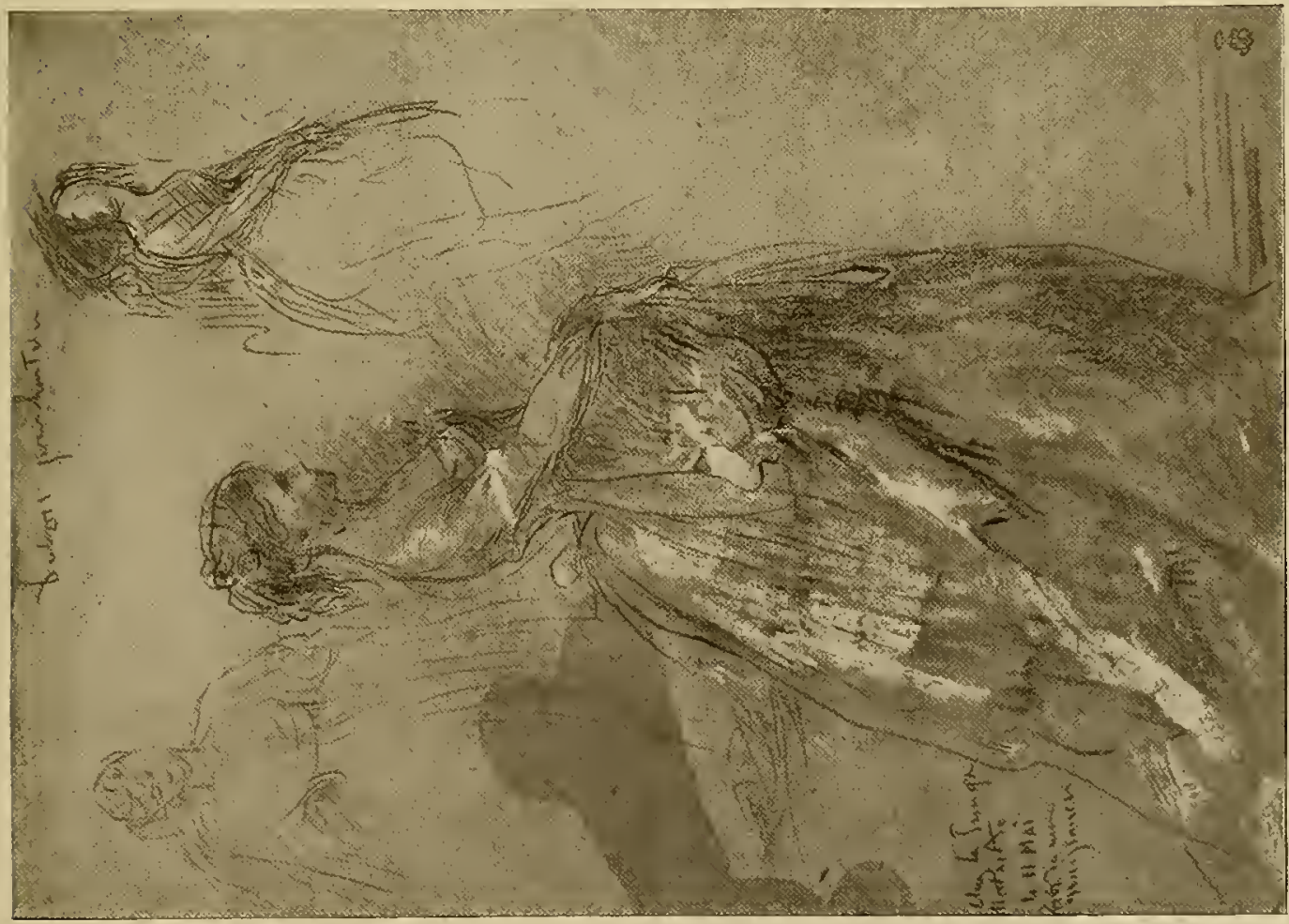



168. $-1^{\circ}$ Le Cercueil de l'Empereur Napoléon III.

$2^{\circ}, 3^{\circ}$ et $4^{\circ}$ Trois croquis de l'Empereur, debout ou

à cheval et en tenue de chasse.

$5^{\circ}$ Le Prince Impérial apprenant ses leçons.

$6^{\circ}$ L'Impératrice en tenue de bal.

Six dessins au crayon noir, dont trois signés et datés.

Exposition École Nationale des Beaux-Arts, Paris, $1894 .-$ No 224 .

Exposition Maison d'Art, Bruxelles, I896. - N॰66.

Salon d'Automne (Rétrospective Carpeau.x), I $907 .-$ No 89 .

Exposition au Jeu de Paume(Tuileries), 19 r2. - No 268.

169. - L'Impératrice Eugénie en toilette de bal.

Dessin au crayon noir rehaussé de blanc.

Signé à gauche avec la mention : Saint-Cloud.

Exposition École Nationale des Beaux-Arts, Paris, I 897 . (Partie du no 248 du catalogue).

Exposition Maison d'Art, Bruxelles, ${ }_{1} 896$. (Partie du no $7^{5}$ du catalogue).

Salon d'Aulomne (Rétrospective Carpeaux), Igo $7 .-\mathrm{No} 9 \mathrm{l}$.

Exposition au Jeu de Paume (Tuileries), Ig T2.- No 267.

17o. - Éludes d'après le Prince Impérial : $1^{\circ}$ La Leçon de violon;

$2^{\circ}$ La Leçon de danse;

$3^{\circ}$ Le Prince en tenue de grenadier. (Étude pour la statue représentant le prince impérial).

Trois dessins à la plume.

Exposition au Jeu de Paume (Tuileries), I 9 I2. - No 304.

171. - Hyde Park. (Londres.)

Onze études d'amazones (Lady Godiva), de cheraux et de chiens.

Dessin au crayon noir et à la plume.

Exposition École Nationale des Beaux-Arts, Paris, I 894. $\mathrm{N}^{\circ} 230$.

Exposition Maison d'Art, Bru.xelles, I 896. - No 68 .

Exposition all Jeu de Paume (Tuileries), I $912 .-$ No 287. 
172. - Lison.

Cinq dessins au crayon noir, dont deux signés et datés : 1872 .

Exposition au Jeu de Paume (Tuileries), I 9 I 2. - No 294.

173. - Visions dans les nuages.

Huit dessins au crayon noirr rehaussé de blanc, et dont l'un est signé à gauche.

Exposition Ecole Nationale des Beaux.Arts, Paris, 1894 . No I 80 .

Exposition Maison d'Art, Bruxelles, I $896 .-$ No 54.

174. - Chevanchée (silhouette de nuage).

Dessin au crayon noir.

Les formes des nuages, dont Carpeaux se plaisait à suivre l'infinie variété, ont inspiré à l'artiste la composition de plusieurs de ses dessins (voir $n^{\circ} 188$ du présent Catalogue).

Exposition Ecole Nationale des Beaux-Arts, Paris, I894. No 160.

Exposition Maison d'Art, Bruxelles, I 896 . - No $7 \mathrm{I}$.

175. - Au Sermon.

Signé à droite et daté : 1863.

Dessin au crayon noir.

Exposition Ecole Nationale des Beaux-Arts, Paris, I894. $\mathrm{N}^{\circ} 252$.

Exposition Maison d'Art, Bruxelles, I 896. - No 76 .

176. - L'Empereur Napoléon III dans son cercueil.

Signé à droite.

Dessin au crayon noir.

Réplique du dessin exécuté pour le prince Impérial et actuellement au musée de Versailles.

Salon d'Automne (Rétrospective Carpeaux), I $907 .-$ No 87. Exposition au Jeu de Paune (Tuileries), I 9 I 2. - No 266. 
177. - Saint Jérôme.

Dessin au crayon noir.

A gauche, cachet de cire avec monogramme.

Exposition au Jeu de Paume (Tuileries), I9I2. - No 301.

178. - Portrait de Watteau.

D’après une estampe prêtée par le marquis de Piennes, à l'époque où l'artiste réunissait des documents pour exécuter sa statue de Watteau pour la ville de Valenciennes.

Dessin à la mine de plomb, rehaussé de blanc.

Exposition au Jeu de Paume (Tuileries), I g I2. - No 283.

179. - Six études d'après Watteau.

Dessin au crayon noir.

Exposition au Jeu de Paume (Tuileries), I 9 I 2. - No 282.

180. - Étude pour le fronton du Pavillon de Flore.

Dessin à l'encre.

Exposition Ecale Nationale des Bexux-Arts, , $894 .-$ No 192.

Exposition Maison d'Art, Bruxelles, $x 896$. - No 59 .

I8I. - Croquis d'Enfants.

Motifs de sculpture décorative.

Huit dessins, dont quatre signés, au crayon noir et à l'encre.

Exposition Ecole Nationale des Beaux-Arts, Paris, I894. No 297.

Exposition Maison d'Art, Bruxelles, ${ }_{1} \$_{96} 6$.

182. - Personnages politiques.

Six caricatures : Gambetta, Crémieux, le Prince Jéròme, etc. Dessin au crayon rehaussé de blanc.

Signés, les uns, en toutes lettres, les autres du monogramme.

Exposition École Nationale des Beaux.Arts, Paris, I 894. $\mathrm{No} 3_{4}$.

Exposition Maison d'Art, Bruxelles, I896. - No 47 .

Salon d'Automne (Rétrospective Carpeaux), 190\%. - No 94 .

Exposition au Jeu de Paume (Tuileries), I 9 I 2. - № 269 . 
183. - Étude de chevaux.

Dessin à droite.

Dessin à la mine de plomb, rehaussé de blanc.

Signé à droite.

184. - Portrait de $M$. le Vicomte de $M \ldots$...

Dessin au crayon noir, rehaussé de blanc.

Exposition Ecole Nationale des Beaux-Arts, Paris, $1894 .-$ $\mathrm{N}^{\circ}{ }_{2} \mathrm{~S}$.

185. - Le Jugement dernier (d'après Michel-Ange).

Dessin au crayon noir.

186. - Cavalier dans la neige.

Signé à gauche.

Dessin rehaussé de gouache.

A figuré à plusieurs expositions sous le titre : Calabrais à cheval par la neige.

Exposition École Nationale des Beaur-Arts, Paris, I $89+.-$ No 235 .

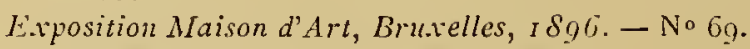

Salon d'Autonne (Rétrospective Carpeaut.r), I907. - No 92.

Exposition au Jeu de Paume (Tuileries), Ig I 2.- No 288.

187. - Une Réunion de politiciens.

Dessin au crayon noir, rehausse de blanc.

Monogramme à droite, avec la date: Páques 72 .

I88. - Chevauchée. (Silhouette de nuage.)

Signé à droite.

Dessin au crayon rehaussé.

E.tposition École Nationale des Beaur-Arts, $1894 .-$ No 240.

189. - Portrait du Marquis de Piennes, écuyer de l'Impératrice.

Dessin au crayon noir.

Salon d'Automne (Rétrospective Carpeauxi), I 907. - No 102.

Expostion au Jeu de Prume (Tuileries), IgI2. - No 279. 
I9o. - Etude pour la statue de Rabelais.

Dix-sept croquis à la plume et au crayon.

Signé à droite, avec mention : "Projet d'une statue à $R a$ blais " (sic).

Exposition Ecole Nationale des Beaux-Arts, I 894.- № 225.

191. - Portrait de M. X...

Pastel.

Haut., o m. 39; larg, o m. 29.

192. - Tête de Vieillard.

Dessin au crayon noir.

193. - Etudes pour la statue du Prince Impérial.

Trois dessins au crayon noir dont l'un est signé à gauche, avec la mention: Palais de Compiègne.

Au verso: Le Prince Impérial prenant sa leçon de danse.

Dessin au crayon noir.

194. - Étude de cheval.

Dessin au crayon noir.

195. - Quatre croquis.

Dessin à la plume.

196. - Projet pour la décoration du Pavillon de Flore.

Dessin au crayon noir et à l'encre.

197. - Etudes d'Hommes et de Femmes.

Trois dessins au crayon noir.

198. $-I^{\circ}$ Homme debout.

$2^{\circ}$ Scène infernale.

$3^{\circ}$ Étude d'après l'Antique.

Trois dessins au crayon noir. 
I99. - Etude de main et dessin, d'après Michel-Ange.

Trois dessins à la plume ou au crayon, et dont l'un est signé.

200. - $I^{\circ}$ Enfant.

$2^{\circ}$ Une bataille.

$3^{\circ}$ Homme assis.

$7^{\circ}$ Fenme.

$5^{\circ}$ Homme assis.

$6^{\circ}$ Femme accroupie.

Six dessins au crayon noir.

201. - Paysage.

Pastel.

Haut., o m. 17 ; larg., o m. 28.

202. - Trois dessins :

$1^{\circ}$ Lampadaire.

Dessin au crayon noir, rehaussé de blanc.

$2^{\circ}$ Étude pour la fontaine de Watteau à Valenciennes.

Dessin au crayon noir.

$3^{\circ}$ A u spectacle.

Dessin au crayon noir.

203. - Trois dessins :

$1^{\circ}$ Buste d'Homme.

Dessin au crayon noir.

$2^{\circ}$ Diane.

Dessin à la plume.

30 Homme assis.

Dessin au crayon noir. 
204. - Études pour le groupe de la Danse. (Théâtre de l'Opéra, Paris.)

$\mathrm{I}^{\circ}$ Recherches pour le groupe sculpté par l'artiste et soumis à Garnier, architecte de l'Opéra, lequel fit considérablement réduire le nombre des figures.

$3^{\circ}$ Portrait de Carpeaux par lui-même.

Quatre dessins au crayon et à la plume.

205. - $1^{\circ}$ Tulipes.

Aquarelle.

$2^{\circ}$ Femme et Jeune Fille agenouillée.

Croquis à la plume.

Au verso :

$3^{\circ}$ Fenme et enfants.

Dessin au crayon noir.

206. - Rabelais.

Trois dessins à la plume, dont un sur papier bleu.

Au verso:

Rabelais dans son fauteuil.

Croquis à la plume.

207. - Projet pour une statue de la Ville de Paris dont l'esquisse est au musée de Valenciennes.

Trois dessins sur papier de couleur, crayon noir rehaussé de blanc.

208. -- I $^{\circ}$ Les Trois Graces.

Étude pour le groupe original dümème sujet.

-- $2^{\circ}$ L'Ève tentée.

Trois dessins à la plume. Au verso, deux dessins du même sujet. 
209. - Une Rue du vieux Paris.

Dessin au crayon noir rehaussé de blanc.

210. - La Négresse.

Étude pour la fontine de l'Observatoire.

Dessin au crayon doir.

21. - Etudes pour le Pavillon de Flore. (Monument des Tuilerịes.)

Six dessins à la plume et au crayon.

2I2. - Flore.

Premier projet pour le bas-relief de Flore, variante de l'exécution détinitive.

Signé dans le bas, au milieu.

Dessin à la plume.

213. - Projet pour le monument: " la Tragédic et la Musique ", première commande faite à Carpeaux pour la décoration de l'Opéra.

Trois dessins au crayon et un dessin à la plume.

214. - La Famille Impériale.

Quatre dessins au crayon noir.

Monogramme de l'artiste, sur le déssin représentant l'Impératrice.

215. - Motifs d'après Watteau.

Quatre dessinins à la mine de plomb.

216. - Gounod.

Deux dessins au crayon noir.

Au verso, un dessin représentanı également Gounod. 

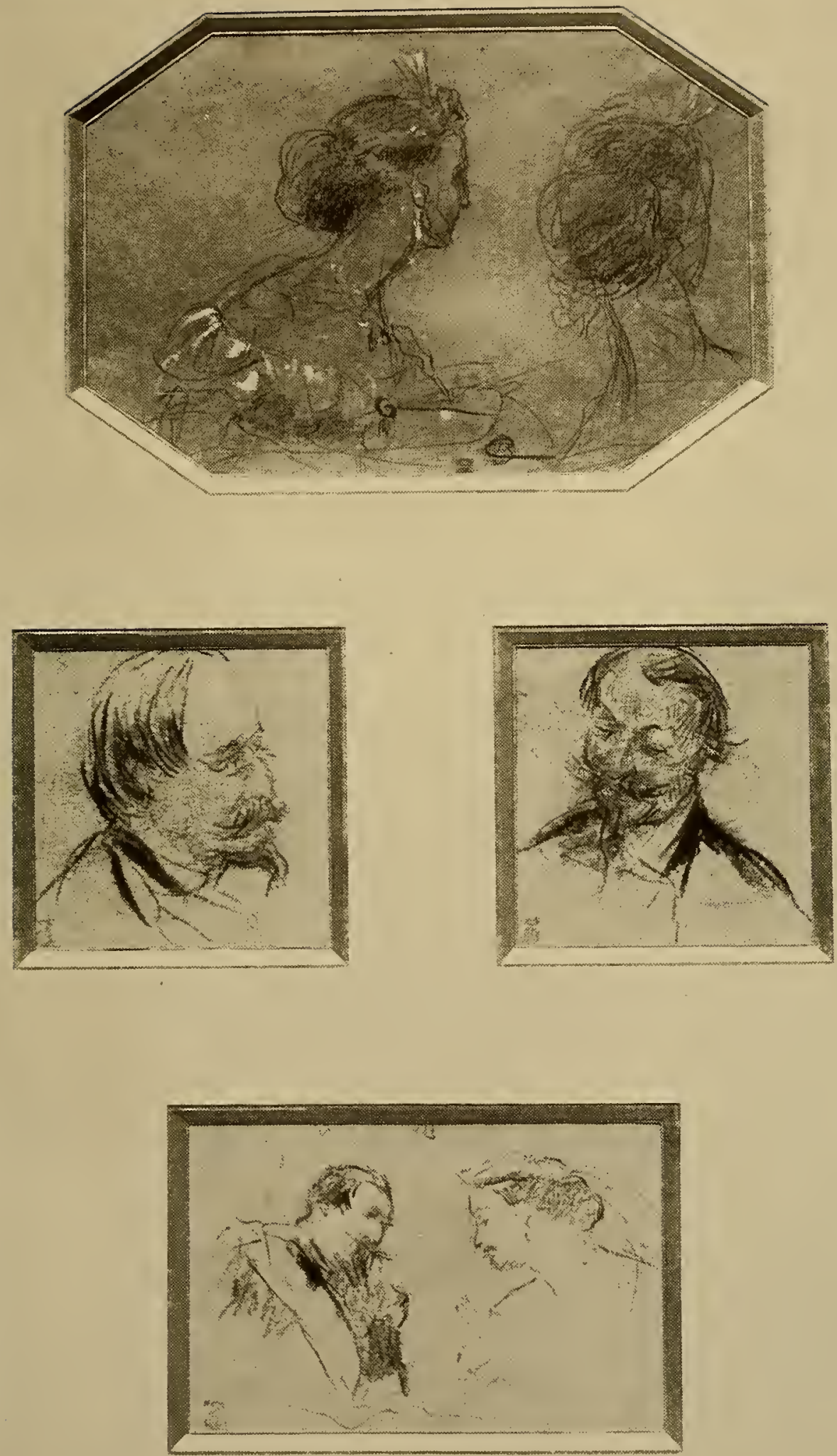

217. - Trois croquis rehaussés de pastel:

$I^{\circ}$ Deux études faites par l'artiste pendant les brillantes réceptions anx Tuileries en $\mathrm{i} 867$, et qui lui servirent pour ses tableaux: Bal costumé aux Tuileries, Bal aux Tuileries, acquis par le muséc du Louvre.

$2^{n}$ Croquis pour le Quadrille officiel à Compiègne, dont le dessin est au musée du Louvre.

218. - Cinq dessins :

$1^{\circ}$ Le Christ guérissant les malades, daprès Rembrandt.

Dessin à la sanguine.

$2^{\circ}$ et $3^{\circ}$ Dentx études, d'après Michel-Ange.

Dessin au crayon noir.

$4^{\circ}$ Dans l'Église.

Dessin au crayon noir rehaussé de blanc.

$5^{\circ}$ Enfants.

Dessin au crayon noir.

2 I9 - Vautours et perroquets.

Deux dessins au crayon noir.

220. - Trois dessins au crayon noir:

$1^{\circ}$ Lion debout.

$2^{\circ}$ Deux Têtes de linns.

30 Lion couché.

Signé et daté : Londres, $18_{72}$.

221. - Deux dessins :

I0 Trpes populaires (Londres). Crayon noir.

$2^{\circ}$ Études à la plume.

222. - Deux dessins au crayon noir rehaussé de blanc:

$I^{\circ}$ Femme se coiffant.

$2^{\circ}$ Les Trois Grâces. 
223. - Saint Sébastien.

Dessin à la plume.

224. - Les Saintes Femmes au tombeau.

Dessin à la plume.

225. - Six études d'après Watteau.

Dessin à la mine de plomb.

Exposition au Jeu de Paume (Tuileries), 19I2.- No 283.

226. - $1^{\circ}$ Deux études pour la statuette de "l'Enfant au cor » (d'après l'Antique).

$2^{\circ}$ Femme debout.

Trois dessins au crayon noir et à la plume.

227. - Deux dessins :

Io Alexandre après le meurtre de Clytus.

Dessin au crayon. (Concours d'école.)

$2^{\circ}$ Cérémonie du sacre d'un roi de France.

Dessin à la plume.

228. - Chevanx et taureaux.

Deux croquis à la plume.

Le croquis : "Taureaux" a servi pour le grand dessin du musée de Valenciennes.

229. - Deux dessins à la plume:

Io Projet de cariatide.

$2^{\circ}$ Groupe d'enfants jouant avec un ane.

Projet pour l'cau-forte du même sujet, dont le cuivre figure au présent catalogue sous le $n^{\circ} 258$. 

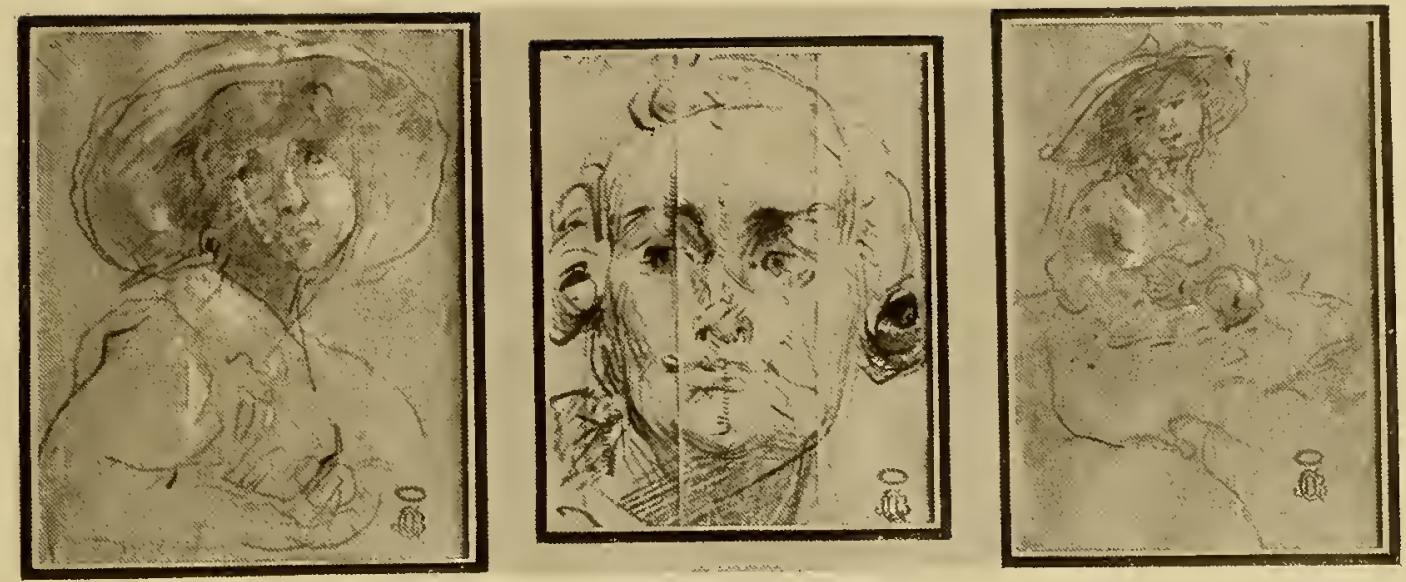

No 166



No 234 

23o. - Etude pour le monument de don Pedro, Empereur du Brésil.

Dessin au crayon noir sur papier teinté.

231. - Trois dessins :

10 Ugolin et ses enfants.

Dessin à la plume, annoté, exécuté par l'artiste pour la commande de la selle destinée à supporter son groupe en terre glaise.

$2^{\circ}$ Variante du groupe d" Ugolin et ses enfants".

Dessin au crayon noir.

30 Étude pou" "Ugolin".

Dessin au crayon noir.

232. - Trois dessins:

Io Daphnis et Chloé.

Croquis à la plume, sur papier bleu.

$2^{\circ}$ Paul et Virginie.

Projet d'un groupe exécuté par l'artiste.

Dessin au crayon noir.

30 Paul et Virginie.

Dessin à la plume.

233. - Deux dessins à la plume:

Io Composition pour la façade du Pavillon de Flore.

$2^{\circ}$ Défense de la Patrie.

Étude pour la décoration de l'Hôtel de Ville deValenciennes.

Dans le bas, l'inscription: La Ville de Valenciennes a bien mérilé de la Patrie, 1793.

234. - Deux dessins :

- La Proclamation de la République.

Sépia rehaussée.

$2^{\circ} \mathrm{Au}$ verso: Un Incendie.

Sépia rehaussée. 
235. - Trois dessins :

I Fenme couchée.

Dessin au crayon noir rehaussé de blanc.

$2^{\circ}$ et $3^{\circ}$ Études.

Deux dessins au crayon noir.

236. - Quatre dessins :

$1^{\circ}$ Femme assise.

Dessin au crayon noir.

$2^{\circ}$ Feuille de croquis à la plume.

$3^{\circ}$ Étude d'après l'antique.

Dessin à la plume.

$4^{\circ}$ Femme assise.

Dessin au crayon noir.

237. - Études de chevaux:

Io Cheval de profil.

Dessin à la plume.

$2^{\circ}$ Cheral se cabrant.

Dessin au crayon noir.

238. - Denx dessins :

$1^{\circ}$ Étude d'après laquelle Carpeaux composa la toile du musée du Louvre, intitulée : Retour des Souverains de la Grande Revue, $186_{7}$, attentat de Berezon'sli.

$2^{\circ}$ Cavaliers.

Deux dessins au crayon noir.

239. - Deux dessins:

I Émeute dans Paris.

Dessin au crayon noir, daté : 1969 .

$2^{\circ}$ Une Rue de Paris pendant la guerre de $1870-187 \mathrm{I}$.

Dessin au crayon noir et à la mine de plomb, daté : I $97^{\text {bre }} 70$. - Sur feuille de papier à lettres portant l'entête : Quartier Général.3me secteur, I7, rue de l'Argonne, Paris, 1870 . 
240. - Réquisition de chevaux, scène du siège de Paris. Pastel.

Signé à droite.

Exposition École Nalionale des Beaux-Arts, Paris, I8gt.No 50.

Exposition au Jeu de Paume (Tuileries), I gI:. - No 290.

241. - Épisodes de la Guerre $\left(1870-I 8_{7} I\right)$.

Cinq croquis a crayon noir. 


\section{ALBUMS DE DESSINS}

\section{PAR CARPEAUX}

242. - Le Siège de Paris (1870-1871).

Album de to croquis au crayon noir, sur 35 feuillets.

243. - Croquis divers : Réunions publiques, Églises, Chevaux. - Londres, $I \delta_{7} I$.

Crayon noir et pastel.

Album de 52 feuillets, avec nombreuses annotations par l'artiste qui a inscrit en première page : Ce carnet appartient a J. Bte Carpeaux, 3t, Brompton Square, South Kensington. Londres, 27 avril $I S_{7} I$.

244. - Types populaires.

Album de +6 feuillets, croquis au crayon noir.

245. - Deux carnets de dessins au crayon noir : $I^{\circ}$ Croquis damarones, Hyde Park. Londres.

29 dessins sur 26 feuillets.

Sur le feuillet de garde, inscription par l'artiste : Ce carnet appartient a $J$. Bte Carpeaux, $3+$, Brompton Square, South Kensinglon. Londres.

$2^{\circ}$ Carnet de poche.

23 pages de croquis avec plusieurs annotations par l'artiste.

246. - Carnet de poche, daté avril 1865.

$7+$ feuillets de croquis.

A la suite du titre : "Livre de mémoire, commencé le $I^{\mathrm{e}_{\mathrm{r}}}$ avril I 865 , l'inscription par l'artiste: "Appartenant à $J$. B ${ }^{1 e}$ Carpeaux, apprenti sculpteur, demeurant à Paris, rue du Faubourg Saint Honoré $n^{\circ} 235$.

247. - Album de 37 croquis.

Sur 3 ; feuillets.

Animaux; sujets mythologiques, classiques et populaires.

Dessins à l'encre et à la mine de plomb. 
248. - Album de $3+$ croquis à la plume.

Sur 3 i feuillets.

249. - La Famille Impériale. - Gounod aux Tuileries.

Album de 40 croquis au crayon noir, sur 29 feuillets.

2.50. - Sujets religieux.

Album de 5 r croquis, sur 46 feuillets.

25 I. - Animaux sauvages, etc.

Album de 60 croquis, sur 5 r feuillets.

252. - Premières idées des principales cunves de Carpeaux.

Album de 60 croquis, sur 43 feuillets.

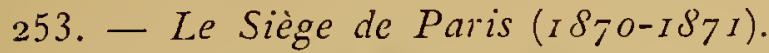

Album de 47 feuillets, avec de nombreuses annotations par l'artiste.

En tête, l'inscription : Ce carnet appartient ì J.-B. Carpeaux, au Palais du L.uxembourg.

254. - Sujets divers.

Album de 30 croquis, sur 30 feuillets.

255. - $\mathrm{I}^{\circ}$ Compositions originales.

181 dessins sur +7 feuillets.

$2^{\circ}$ Compositions d'après l'antique.

25 dessins sur $\mathrm{z} \tau$ feuillets.

En un album à reliure maroquin rouge choisie par J.-B. Carpeaux qui y colla lui-même toute une série de dessins à la plume exécutés sur papier pelure, dessins qu'il se proposait de graver par la suite. Plusieurs études d'après des modèles ayant posé pour ses auvres : Napolitain, la Toilette, Frère et Sæur, projets de groupes, etc.

Au feuillet $n^{\circ} 12$, l'annotation, par l'artiste : Valenciennes, le I I mai I 860 . Edtution de Shakespeare, l'anniversaire de ma naissance. 


\section{CUIVRES POUR EAUX-FORTES ( $\left.{ }^{*}\right)$ GRAVÉS PAR CARPEAUX}

256. - Les Brigands calabrais.

Cuivre pour eau-forte.

Signé des initiales : $J .-C$.

Haut., o m. I ; larg., o m. 15.

Exposition École Nationale des Beau $x^{\circ}$ Arts, Paris, I $894 .-$ No 435.

Salon d'A utomne (Rétrospective Carpeau.x), I907. - No 147.

257. - Ronde d'Enfants.

Cuivre pour eau-forte.

Haut., o m. I ; larg., o m. i4 I/2.

Exposition École Nationale des Beaux-Arts, Paris, $1894 .-$ $\mathrm{No} 436$.

Salon d'Automne (Rétrospective Carpeau.x), 1907. - No 148

258. - Enfants jouant avec un ane.

Cuivre pour eau-forte.

Haut, o m. II; larg., $0 \mathrm{~m} .14 \mathrm{r} / 2$.

Exposition École Nationale des Beaux-Arts, Paris, I894. No 437 .

Salon d'Automne (Rétrospective Carpeaux), I $907 .-$ No 149.

259. - Portrait d'Homme.

Cuivre pour eau-forte.

Signé, avec dédicace.

Haut., o m. ıо larg., o m. 6.

* Les cuivres pour eaux-fortes seront vendus avec droit deedition. 


\title{
DESSINS \\ PAR EUGÈNE DELACROIX
}

\author{
$\left(179^{8-1853)}\right.$
}

260. - Etudes de chiens.

Treize croquis à la mine de plomb.

A droite, estampille de la vente Delacroix, 1864 .

26r. - Étude de jambe.

Dessin au crayon rouge et noir.

A droite, estampille de la vente Delacroix, 1864 .

262. - Torse d'Homme.

Dessin au crayon rouge et noir.

A droite, estampille de la vente Delacroix, 1864 .

263. - Sept croquis d'anatomie.

Dessin au crayon rouge et noir.

A droite, estampilie de la vente Delacroix, 1864 .

264. - Sept croquis d'anatomie.

Dessin au crayon rouge et noir.

A droite, estampille de la vente Delacroix, I864.

265. - Études de muscles.

Dessin au crayon rouge et noir.

A droite, estampille de la vente Delacroix, 1864.

266. - Étude des muscles fléchisseurs de la jambe.

Dessin au crayon rouge et noir.

Estampille de la vente Delacroix, 1864. 
267. - $1^{\circ}$ Femme couchée.

$2^{\circ}$ Torse d'Homme.

Dessin à la mine de plomb.

Estampille de la vente Delacroix, I864.

268. - Études de torse et de bras.

Deux dessins à la mine de plomb, crayon noir et rouge

Estampille de la vente Delacroix, i 864.

269. - Études de mains et de pieds.

Deux dessins au crayon noir.

Estampille de la vente Delacroix, 1864 .

270. - $1^{\circ}$ Composition allégorique.

Dessin au crayon.

$2^{\circ}$ Étude de bras.

Dessin à la plume.

Estampille de la vente Delacroix, 1864.

271. - $1^{\circ}$ Torse d'Homme.

$2^{\circ}$ Étude de cavalier.

Deux dessins au crayon noir.

Estampille de la vente Delacroix, 1864.

272. - Deux dessins au crayon noir et rouge : Études de jambes et du bassin.

Estampille de lavente Delacroix, 1864 .

273. - $1^{\circ}$ Etude de bras.

$2^{\circ}$ Femme assise.

3० Honme couché.

Trois dessins à la mine de plomb.

Estampille de la vente Delacroix, 1864 . 
274. $-1^{\circ}$ Etude de jambes.

$2^{\circ}$ Soldats combattant.

Deux dessins à la mine de plomb.

Estampille de la vente Delacroix, 1864 .

275. - Composition pour "le Dante».

Dessin au crayon noir.

Estampille de la vente Delacroix, 1864 .

276. - Deux feuilles de croquis à la mine de plomb.

Estampille de la vente Delacroix, 1864 .

277. - $1^{\circ}$ Etude de draperie. Buste de Femme.

Dessin au crayon noir.

$2^{\circ}$ Étude de muscles.

Dessin au crayon rouge et noir.

Estampille de la vente Delacroix, 1864 .

278. - Étude de bras, de jambes et de clavicules.

Deux dessins à la mine de plomb et at crayon rouge.

Estampille de la vente Delacroix, I864.

279. $-1^{\circ}$ Homme écrivant.

$2^{\circ}$ Cinq croquis.

Dessin à la mine de plomb.

Estampille de la vente Delacroix, 1864 .

280. - $\mathrm{I}^{\circ}$ Buste d'Homme.

$2^{\circ}$ Dessin pour " l'Enfer " du Dante.

Deux dessins à la mine de plomb.

Estampille de la vente Delacroix, 1864 . 
281. - $1^{\circ}$ Étude de muscles.

Dessin à la sépia.

$2^{\circ}$ Homme couché.

Dessin à la mine de plomb.

Estampille de la vente Delacroix, 1864.

282. - Études d'anatomie: Muscles extenseurs.

Deux dessins à la mine de plomb et au crayon rouge.

Estampille de la vente Delacroix, i 864 .

283. - Etude des muscles de la jambe.

Deux dessins au crayon rouge et noir.

Estampille de la vente Delacroix, 1864 .

284. - Etudes d'anatomie.

Trois dessins au crayon rouge et noir.

Estampille de la vente Delacroix, 1864.

285. - Études d'anatomie.

Deux dessins au crayon rouge et noir.

Estampille de la vente Delacroix, 1864 .

286. - Études d'anatomie.

Quatre dessins au crayon noir, à la mine de plomb et au crayon rouge. L'un des dessins est daté : 98 bre 55. Dieppe.

Estampille de la vente Delacroix, i 864 .

287. - Croquis d'anatomie.

Quatre dessins à l'encre, à la mine de plomb et au crayon rouge et noir.

288. - Études d'anatomie.

Six feuilles.

Dessin à la mine de plomb. 
289. - Études d'anatomie.

Sept feuilles.

Dessin à la mine de plomb et au crayon rouge et noir.

29o. - Motifs de décoration et d'architecture.

Six feuilles.

Dessin à la mine ide plomb.

Estampille de la vente Delacroix, i 864 .

29I. - Études de muscles.

Deux feuilles.

Dessin au crayon rouge et noir.

Estampille de la vente Delacroix, i 864 .

292. - Deux feuilles :

$I^{\circ}$ Études de bras.

Dessin au crayon rouge et noir.

$2^{\circ}$ Étude de mains.

Dessin au crayon noir.

Estampille de la vente Delacroix, 1864 .

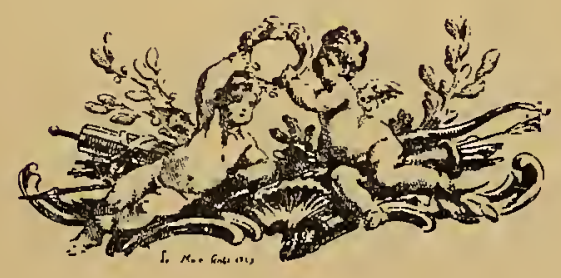




SMITHSONIAN INSTTTUTION LIBAARIES

39088011320801

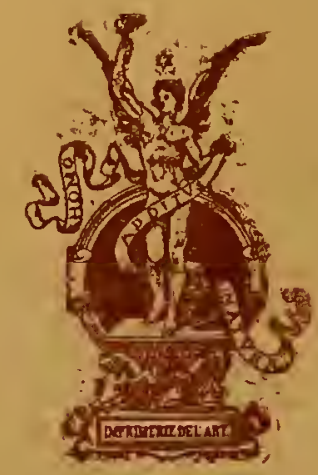

